\title{
A FIRE-ACE/SHEBA Case Study of Mixed-Phase Arctic Boundary Layer Clouds: Entrainment Rate Limitations on Rapid Primary Ice Nucleation Processes
}

\author{
Ann M. Fridlind, ${ }^{*}$ BastiaAn VAn Diedenhoven, ${ }^{+}$Andrew S. ACKerman, $*$ \\ Alexander Avramov, ${ }^{+}$AgnieszKa Mrowiec, ${ }^{+}$Hugh Morrison, \\ PAQUiTA ZuIDEMA, ${ }^{@}$ AND MATTHEW D. SHUPE ${ }^{\&}$ \\ * NASA Goddard Institute for Space Studies, New York, New York \\ ${ }^{+}$Columbia University, New York, New York \\ \# National Center for Atmospheric Research, Boulder, Colorado \\ @ Rosenstiel School of Marine and Atmospheric Science, University of Miami, Miami, Florida \\ \& Cooperative Institute for Research in Environmental Sciences, University of \\ Colorado, and NOAA/ESRL/PSD, Boulder, Colorado
}

(Manuscript received 8 February 2011, in final form 2 August 2011)

\begin{abstract}
Observations of long-lived mixed-phase Arctic boundary layer clouds on 7 May 1998 during the First International Satellite Cloud Climatology Project (ISCCP) Regional Experiment (FIRE)-Arctic Cloud Experiment (ACE)/Surface Heat Budget of the Arctic Ocean (SHEBA) campaign provide a unique opportunity to test understanding of cloud ice formation. Under the microphysically simple conditions observed (apparently negligible ice aggregation, sublimation, and multiplication), the only expected source of new ice crystals is activation of heterogeneous ice nuclei (IN) and the only sink is sedimentation. Large-eddy simulations with size-resolved microphysics are initialized with IN number concentration $N_{\text {IN }}$ measured above cloud top, but details of IN activation behavior are unknown. If activated rapidly (in deposition, condensation, or immersion modes), as commonly assumed, IN are depleted from the well-mixed boundary layer within minutes. Quasi-equilibrium ice number concentration $N_{i}$ is then limited to a small fraction of overlying $N_{\text {IN }}$ that is determined by the cloud-top entrainment rate $w_{e}$ divided by the number-weighted ice fall speed at the surface $v_{f}$. Because $w_{c}<1 \mathrm{~cm} \mathrm{~s}^{-1}$ and $v_{f}>10 \mathrm{~cm} \mathrm{~s}^{-1}, N_{i} / N_{\mathrm{IN}} \ll 1$. Such conditions may be common for this cloud type, which has implications for modeling IN diagnostically, interpreting measurements, and quantifying sensitivity to increasing $N_{\text {IN }}$ (when $w_{e} / v_{f}<1$, entrainment rate limitations serve to buffer cloud system response). To reproduce observed ice crystal size distributions and cloud radar reflectivities with rapidly consumed IN in this case, the measured above-cloud $N_{\text {IN }}$ must be multiplied by approximately 30 . However, results are sensitive to assumed ice crystal properties not constrained by measurements. In addition, simulations do not reproduce the pronounced mesoscale heterogeneity in radar reflectivity that is observed.
\end{abstract}

\section{Introduction}

Observations indicate that the Arctic has warmed at roughly twice the global average rate since the preindustrial period, and that trend is expected to continue during this century (Solomon et al. 2007). However, climate model predictions vary considerably, owing at least in part to the complexity of atmosphere-ice-ocean interactions and a scarcity of the data required to study them (Randall et al. 1998; Sorteberg et al. 2007). Differences in climate model

Corresponding author address: Ann Fridlind, NASA Goddard Institute for Space Studies, 2880 Broadway, New York, NY 10025. E-mail: ann.fridlind@nasa.gov representation of clouds have been targeted as a cause for spread in Arctic climate predictions (Inoue et al. 2006; Gorodetskaya et al. 2008; Holland et al. 2008).

It is therefore a research objective to generate microphysically detailed, high-resolution simulations of the most relevant cloud types in order to understand the dominant processes and improve their necessarily simplified representation in climate models. Because of the many known gaps in our knowledge of cloud processes, comprehensive field experiment case studies are required to evaluate simulation fidelity. Here we consider an observed case of low-level mixed-phase clouds, a common and persistent cloud type over Arctic sea ice during the spring and autumn transition seasons (Shupe et al. 2006), 
when sea ice is changing most rapidly in a manner that may be associated with cloud processes (e.g., Zhang et al. 1996; Dong et al. 2001). This cloud type also appears to be particularly poorly represented in climate models owing at least in part to a lack of understanding of the relevant microphysical processes (Prenni et al. 2007).

Of leading importance for constraining detailed simulations of mixed-phase boundary layer clouds are in situ measurements of water droplet and ice crystal size distribution, ice crystal habit, and ice nucleus (IN) number concentration $N_{\text {IN }}$ active under in-cloud conditions. Ancillary meteorological measurements are required to provide model initial and boundary conditions, and ground-based cloud radar measurements provide valuable additional constraints on model performance (e.g., Fan et al. 2009; van Diedenhoven et al. 2009). To our knowledge, only three field experiments to date have provided all such measurements for single-layer cases of shallow mixed-phase cloud that are most suitable for basic modeling case studies: the 1998 First International Satellite Cloud Climatology Project (ISCCP) Regional Experiment-Arctic Cloud Experiment (FIRE-ACE)/ Surface Heat Budget in the Arctic (SHEBA) campaign (Curry et al. 2000), the 2004 Mixed-Phase Arctic Cloud Experiment (M-PACE; Verlinde et al. 2007), and the 2008 Indirect and Semi-Direct Aerosol Campaign (ISDAC; McFarquhar et al. 2011).

Perhaps the most extensively studied measurements to date were obtained on 10 October during M-PACE in a supercooled boundary layer cloud (mixed-phase layer circa $-9^{\circ}$ to $-16^{\circ} \mathrm{C}$ ) that formed over the ice-free Beaufort Sea under clean, cold-air outbreak conditions (McFarquhar et al. 2007). In a broad model intercomparison study based on these observations and organized in association with the Global Energy and Water Cycle Experiment (GEWEX) Cloud System Study (GCSS) program, it was found that even high-resolution models with relatively sophisticated microphysics, when initialized and forced identically, produced widely differing results (Klein et al. 2009). Other studies of the case identified a controlling role for activated IN concentration in determining cloud properties through the regulation of heterogeneous ice formation (Fridlind et al. 2007; Prenni et al. 2007; Morrison et al. 2008; Fan et al. 2009; Solomon et al. 2009; Avramov and Harrington 2010), consistent with analyses of earlier observed cases (e.g., Pinto 1998; Jiang et al. 2000). However, M-PACE modeling studies also reported large differences in the sensitivity of cloud properties to abovecloud $N_{\text {IN }}$, likely caused at least partly by differences in assumed ice crystal properties (Avramov and Harrington 2010); as an aside we note that this sensitivity to abovecloud $N_{\text {IN }}$ assumes Arctic boundary layer IN sources to be negligible (e.g., Pinto 1998; Harrington and Olsson
2001). Finally, a subset of modeling studies concluded that $N_{\text {IN }}$ measured above cloud were insufficient to explain ice crystal number concentrations measured in the boundary layer (e.g., Fridlind et al. 2007; Morrison et al. 2008; Fan et al. 2009), although it remains unknown whether large uncertainties assigned to observed ice crystal number concentrations (e.g., factor of 5; Fridlind et al. 2007) were adequate to account for errors associated with ice crystal shattering on instrument probes (e.g., Korolev and Isaac 2005; Korolev et al. 2011).

Modeling studies based on data gathered during the FIRE-ACE/SHEBA campaign (hereafter referred to as SHEBA) have also prominently identified the mechanisms of ice formation in mixed-phase boundary layer clouds as a leading source of uncertainty in model results (Girard and Curry 2001; Lohmann et al. 2001; Morrison and Pinto 2005; Morrison et al. 2005; Morrison and Pinto 2006; Yuan et al. 2006; Sandvik et al. 2007; de Boer et al. 2009). During SHEBA, observations of supercooled boundary layer clouds that formed under polluted conditions over sea ice on 7 May 1998 (mixed-phase layer circa $-18^{\circ}$ to $-20^{\circ} \mathrm{C}$, droplet number concentration $N_{d} \approx 200 \mathrm{~cm}^{-3}$, and $N_{\mathrm{IN}} \approx 2 \mathrm{~L}^{-1}$ ) provide a climatologically important contrast to the 10 October M-PACE case of clean conditions over open ocean $\left(N_{d} \approx 40 \mathrm{~cm}^{-3}\right.$ and $\left.N_{\mathrm{IN}} \approx 0.2 \mathrm{~L}^{-1}\right)$. The 7 May case has therefore been used as the basis for a follow-on model intercomparison study coordinated through GCSS (Morrison et al. 2011). From the standpoint of microphysical processes, the 7 May GCSS SHEBA case is uniquely simple owing to high $N_{d}$ and relatively sparse concentrations of unrimed, nondendritic ice crystals, as discussed further below. This distinguishes it from the 10 October M-PACE case, with active drizzle and riming, and from the more recently observed 8 April ISDAC case, with active aggregation of dendrites (Avramov et al. 2011).

Here we develop an adjusted version of the 12-h GCSS SHEBA case (see appendix) in order to better represent the last $2 \mathrm{~h}$, when in situ ice particle size distribution measurements were made. We use a largeeddy simulation code with size-resolved microphysics to simulate the coupling of dynamical and mixed-phase microphysical processes. Our principal objective is to determine whether the mean $N_{\text {IN }}$ observed above cloud is adequate to explain mean observed boundary layer ice properties in simulations that are consistent with all other available observations. Since in situ measurements of ice crystal total number concentration were unreliable at sizes smaller than a poorly characterized threshold (e.g., Korolev et al. 2011), we compare simulations with 1) in situ measurements of the size distribution of ice with maximum dimension larger than $200 \mu \mathrm{m}$ and 2) groundbased remote sensing measurements of cloud radar 
reflectivity and mean Doppler velocity. Below we first describe the observations (section 2) and the model (section 3). We present a range of simulations using several approaches to represent IN and compare results with observations (section 4). Conclusions and implications are then summarized (section 5).

\section{Observations}

The 7 May 1998 flight of the National Center for Atmospheric Research (NCAR) C-130 aircraft was, to our knowledge, the only flight over SHEBA surface instruments that took place in a long-lived $(>12 \mathrm{~h})$ mixedphase boundary layer cloud deck without the overlying cloud layers that were commonly present (Wylie 2001). From the aircraft, we use measurements from a cloud particle imager (CPI), forward scatter spectrometer probe (FSSP-100), and two-dimensional cloud (2D-C) optical array probe (Lawson et al. 2001; Zuidema et al. 2005; Lawson and Zuidema 2009). We adopt the analysis of aerosol and IN data prepared for the GCSS SHEBA case (Morrison et al. 2011), which was based on aircraft measurements from a condensation nucleus counter (Yum and Hudson 2001) and counterflow diffusion chamber (CFDC; Rogers et al. 2001; Prenni et al. 2009). We use 6-h soundings and hourly surface measurements compiled for use by modelers (Persson et al. 2002; Beesley et al. 2000), which include liquid water path derived from microwave radiometer measurements (Liljegren 2000). We derive large-scale forcings from the National Centers for Environmental Prediction (NCEP)/NCAR 40-yr reanalysis project (Kalnay et al. 1996). We use radar reflectivity and mean Doppler velocity measurements from a $\mathrm{K}_{\mathrm{a}}$-band millimeter-wavelength cloud radar (MMCR; Shupe et al. 2001; Intrieri et al. 2002; Shupe et al. 2006).

In brief overview, on 7 May 1998 the SHEBA ice station was located at roughly $75^{\circ} \mathrm{N}, 165^{\circ} \mathrm{W}$ beneath a widespread boundary layer cloud deck (Fig. 1) advecting to the northeast at about $5 \mathrm{~m} \mathrm{~s}^{-1}$. During the 1200 2400 UTC period of the GCSS SHEBA case, MMCR measurements indicate cloud top decreasing from roughly 600 to $400 \mathrm{~m}$ (Morrison et al. 2011, their Fig. 2). Aircraft measurements were limited to the last $2 \mathrm{~h}$ of this time period, 2200-2400 UTC. Several passes were made through the cloud layer (cloud droplets present), and two longer legs sampled ice properties beneath cloud base (Fig. 2).

Although the best available aircraft altitude data indicate unphysically low elevations during a short period of the near-surface leg, here we use the altitude data only to separate particle size distribution measurements into in-cloud and below-cloud categories. At reported altitudes of 310-430 m, all FSSP concentrations indicate highly peaked droplet size distributions that were by

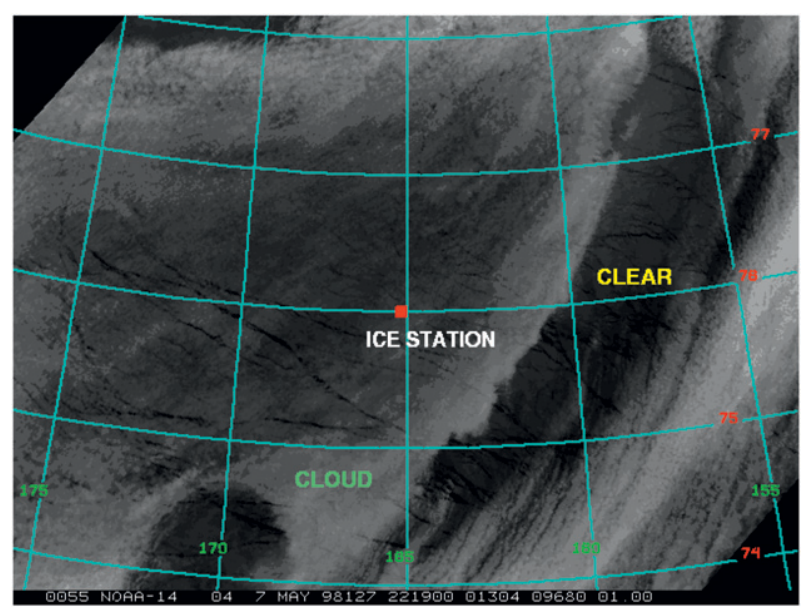

FIG. 1. Advanced Very High Resolution Radiometer (AVHRR) channel $4(10.5-12 \mu \mathrm{m})$ infrared satellite image at 2219 UTC 7 May 1998. Figure reproduced from experiment Web site.

contrast absent below $280 \mathrm{~m}$ (Fig. 3), thus indicating a cloud base range of $280-310 \mathrm{~m}$ that is reasonably consistent with ground-based lidar measurements (not shown). We use FSSP measurements only during these in-cloud time periods and only for diameters less than $20 \mu \mathrm{m}$ (Fig. 3a). We use ice measurements only below cloud base, noting that ice properties typically vary little with elevation in this cloud type (e.g., McFarquhar et al. 2007, 2011). We also use 2D-C data only at maximum dimensions greater than $200 \mu \mathrm{m}$ (Fig. 3b), where shattering effects on number concentrations could be less than about $20 \%$ at the small characteristic ice particle sizes observed here (Field et al. 2006). However, owing to the high degree of uncertainty associated with all optical array probe measurements (Korolev and Isaac 2005; Korolev et al. 2011), we perform an integrated analysis of the in situ and remote sensing measurements.

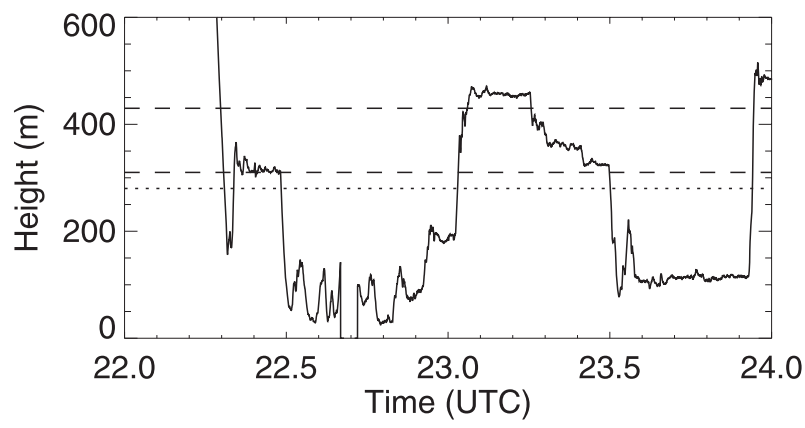

FIG. 2. Reported near-surface elevation of the C-130 aircraft during 2200-2400 UTC 7 May 1998 (solid line). Based on FSSP measurements, flight times are identified as in cloud $(310-430 \mathrm{~m}$ bounded by dashed lines) and below cloud base ( $280 \mathrm{~m}$ indicated by dotted line). 

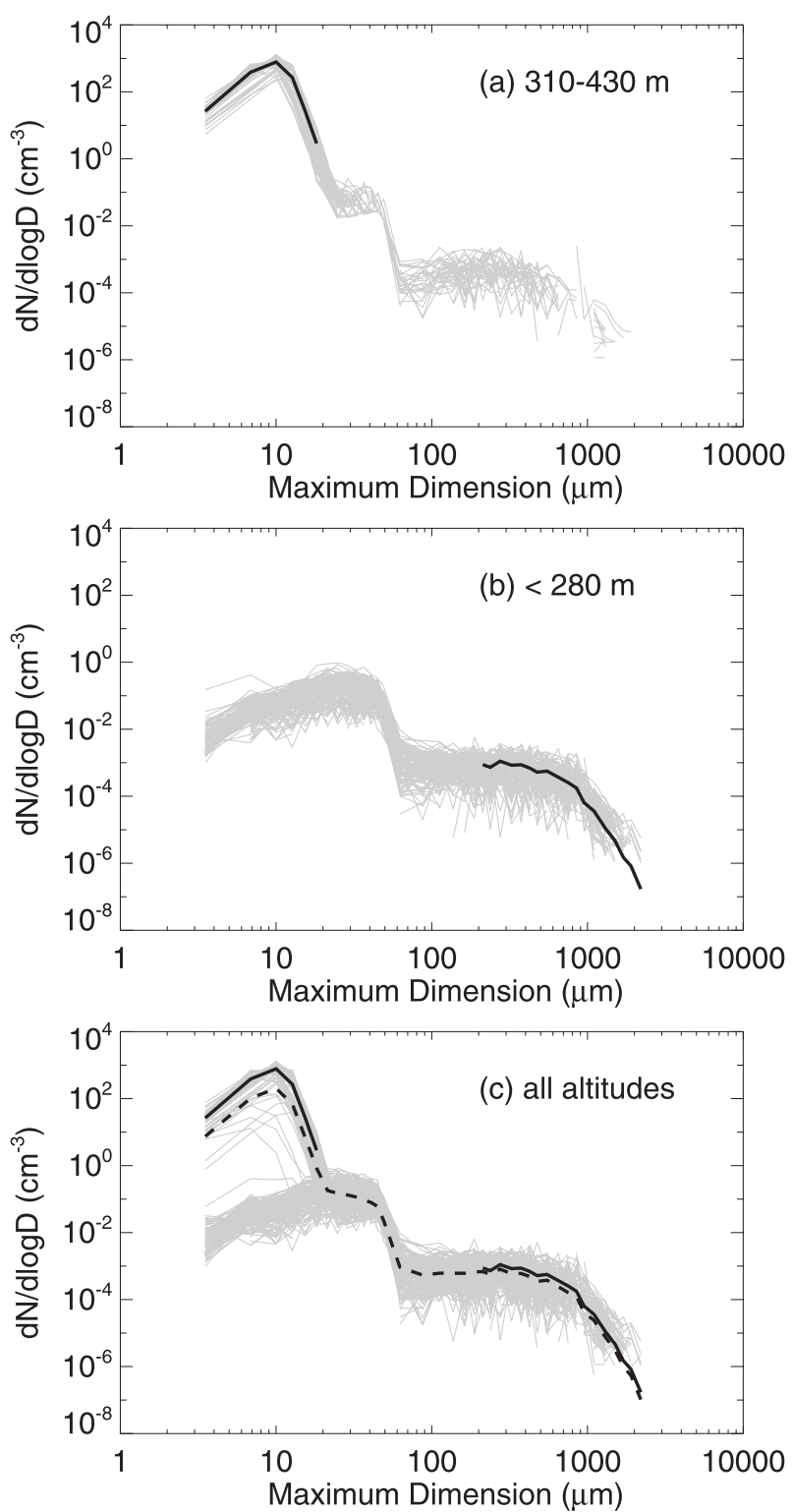

FIG. 3. Observed hydrometeor size distributions measured with FSSP and 2D-C probes during 2229-2359 UTC 7 May 1998 (a) at 310-430 m, (b) below $280 \mathrm{~m}$, and (c) at all altitudes. Mean distributions in (a) and (b) shown in black solid lines for limited size ranges are reproduced in (c) for comparison with mean values at all elevations shown in black dashed line for all sizes.

\section{Model description}

\section{a. Dynamics}

We use the Distributed Hydrodynamic Aerosol and Radiative Modeling Application (DHARMA) code, which treats dynamics using a large-eddy simulation (LES) model (Stevens et al. 2002). We use a horizontal domain that is $3.2 \mathrm{~km}$ on a side, roughly 7 times the boundary layer depth. A vertical extent of $1 \mathrm{~km}$ allows boundary layer depth evolution that is not affected by damping of gravity waves above $800 \mathrm{~m}$ through relaxation of potential temperature and horizontal winds toward their time-varying horizontal averages with a time scale of $100 \mathrm{~s}$, applied at full strength at the domain top and decreasing as sinesquared to zero at $800 \mathrm{~m}$. Grid spacing is uniform horizontally $(50 \mathrm{~m})$ and vertically $(10 \mathrm{~m})$. A dynamic Smagorinsky model (Kirkpatrick et al. 2006) is used to compute subgrid-scale mixing. Surface turbulent fluxes are computed from Monin-Obukhov similarity theory using the dimensionless profiles of Businger et al. (1971) with a turbulent Prandtl number of unity and a von Kármán constant of 0.41 . Skin water vapor is assumed saturated with respect to ice at the skin temperature. A surface roughness of $0.4 \mathrm{~mm}$ is assumed for momentum, water vapor, and heat (cf. Brunke et al. 2006). Horizontal winds are nudged toward their initial profiles with a 1-h time scale. The domain is translated with mean cloud-layer winds $\left(1.8 \mathrm{~m} \mathrm{~s}^{-1}\right.$ westerly and $4.3 \mathrm{~m} \mathrm{~s}^{-1}$ southerly) to minimize errors associated with advection and allow vertical wind speed to dictate the maximum advective Courant number. A 5-s dynamical time step is taken unless the Courant number exceeds 0.8 (the strongest vertical wind speeds increase the total number of time steps by about $5 \%$ in a typical simulation here). Halving vertical and horizontal grid spacing to 5 and $25 \mathrm{~m}$, respectively, and halving the maximum time step to $2.5 \mathrm{~s}$ decreases cloud-top entrainment and increases liquid water path by about $10 \%$, suggesting that the baseline resolution allows for reasonable representation of boundary layer dynamics when using DHARMA for this case.

The specified profile of horizontally uniform largescale subsidence is treated separately from the resolved vertical winds and only appears through a source term for each prognostic variable $\phi$, computed through firstorder upwind advection as $-w_{\mathrm{LS}}=-\partial \phi / \partial z$, where $z$ is altitude (cf. Wyant et al. 1997; Ackerman et al. 2009). We note that the cloud-top entrainment rate is computed throughout as the sum of the subsidence rate at the mean height of the boundary layer top (which is the same as cloud top here) plus the rate of change of mean boundary layer depth (cf. Faloona et al. 2005, their Eq. 2).

\section{b. Microphysics}

We use size-resolved microphysics based on the Community Aerosol-Radiation-Microphysics Application (CARMA) code. The microphysical formulations for warm and cold clouds are described by Ackerman et al. (1995) and Jensen et al. (1998), respectively. An earlier version of the mixed-phase formulation is described by Fridlind et al. (2007), and modifications since that study 
are described below. The linkages between microphysics and dynamics are described by McFarlane et al. (2002, their appendix B).

We use 32 mass-doubling bins each for droplets and ice, where the mass of the smallest bin in each grid is that of a droplet with diameter $2 \mu \mathrm{m}$. The mass of the largest bin is set by the requirement that it contain negligible ice under simulated conditions. Time substepping is employed with a minimum step of $0.2 \mathrm{~s}$ to locally resolve fast microphysical processes such as droplet activation and condensational growth. Aerosols are initialized as specified in the GCSS SHEBA case and treated diagnostically (Clark 1974) to avoid the need for 1) aerosol source terms, which are unknown, and 2) core second moments to restore aerosol size dispersion upon droplet evaporation (Ackerman et al. 1995), which are computationally expensive.

We treat ice in each size bin using the approach developed by Böhm (1989, 1992a,b,c, 1994, 1999, 2004), which provides an integrated treatment of fall speeds and collision efficiencies for ice and liquid particles based on four properties of each participating particle type: mass, maximum dimension, projected area, and aspect ratio. We use size-dependent coalescence efficiencies for water droplets (Beard and Ochs 1984), a coalescence efficiency of unity for liquid-ice collisions and 0.1 for ice-ice collisions of nondendritic crystals under dry-growth conditions (e.g., Mitchell 1988; Wang and Chang 1993). Results are negligibly impacted by increasing the ice-ice collision efficiency to 0.25 or 0.3 (e.g., Mitchell 1988; Girard and Blanchet 2001). We neglect any turbulence effects on the gravitational collection process, which are likely to be minimal under the relatively weak dynamical conditions of this case.

To approximate the impact of ice habit on vapor deposition and sublimation rates, capacitance is calculated for oblate spheroids [Pruppacher and Klett 1997, their Eq. (13-78)], where the aspect ratio is taken as the ratio of minor to major axis and major axis is maximum dimension. We consider the impact of reduced capacitance in a sensitivity test below: 1) the ratio of capacitance to maximum dimension is specified to be 0.35 for all particle sizes [Westbrook et al. 2008, plate aspect ratio of 0.1 in their Eq. (3)], and 2) particles of 120-240- $\mu \mathrm{m}$ maximum dimension are assumed to comprise a linearly increasing fraction of aggregates with a ratio of capacitance to maximum dimension reduced to 0.25 (Westbrook et al. 2008).

\section{c. Ice properties}

Ice is commonly represented in microphysics schemes by a fixed number of types such as plates or dendrites with predetermined properties that are not varied on a casespecific basis (e.g., Lynn et al. 2005). Less commonly, ice properties may be dynamically predicted (e.g., Morrison and Grabowski 2008; Hashino and Tripoli 2007), allowing case-specific properties to emerge in simulations. However, since ice properties vary significantly even within basic habit classes, and evaluating the prediction of ice crystal habit is not an objective of this study, here we choose case-specific model settings to represent the observed ice properties. Since the ice properties needed by this model are not directly measured (viz., maximum diameter, projected area, and aspect ratio as a function of ice particle mass), the remainder of this section provides an analysis of observations to derive ice properties consistent with the available CPI, 2D-C, and MMCR measurements.

Manual examination of the available CPI images indicates an array of crystal shapes (e.g., Fig. 4) that is consistent with past observations at $-16^{\circ}$ to $-20^{\circ} \mathrm{C}$ (e.g., Magono and Lee 1966; Korolev et al. 1999) and laboratory observations of ice grown at those temperatures under conditions of $10 \%-20 \%$ ice supersaturation (Bailey and Hallett 2002; Bacon et al. 2003; Bailey and Hallett 2004). A minority are relatively pristine plates with some degree of transparency (habit class P1a). A few plates have sectorlike branches, consistent with the warm end of the boundary layer temperature range (P1b; Magono and Lee 1966) or are nonisometric (e.g., Magono and Lee 1966; Bacon et al. 2003). Most ice crystals appear polycrystalline, including plates with spatial sectors (P5a) and radiating assemblages of plates (P6a). Some are small assemblages of minute plates or irregular germs (G5 and G6; Magono and Lee 1966; Bailey and Hallett 2004). Many larger crystals are what Bailey and Hallett (2004, p. 521) refer to as "jumbled arrangements of poorly formed but faceted plates or polyhedra of nonhexagonal shape" that at high supersaturation appear as "spatially extended forms."

Historically it has been common to express the relationship of particle maximum dimension $D$ to mass $m$ through power laws of the form $m=a D^{b}$. We use several mass-dimensional relationships to span our ice mass grid piecewise. For instance, when ice crystals with $D>120 \mu \mathrm{m}$ are assumed to be radiating assemblages of plates, ice with $D<5 \mu \mathrm{m}$ is treated as spherical, and ice in the transition size range is represented based on a power law transition between the mass of a sphere with $D=5 \mu \mathrm{m}$ and the mass of a radiating plate with $D=120 \mu \mathrm{m}$ (Table 1). To choose a baseline mass-dimensional relationship for the largest particles, we also considered two other habit choices based on ice shapes seen in CPI images: pristine hexagonal plates and aggregates that include plates (see Table 1). As an observation-based test of the validity of each candidate relation, we compare MMCR measurements with 35-GHz reflectivities 


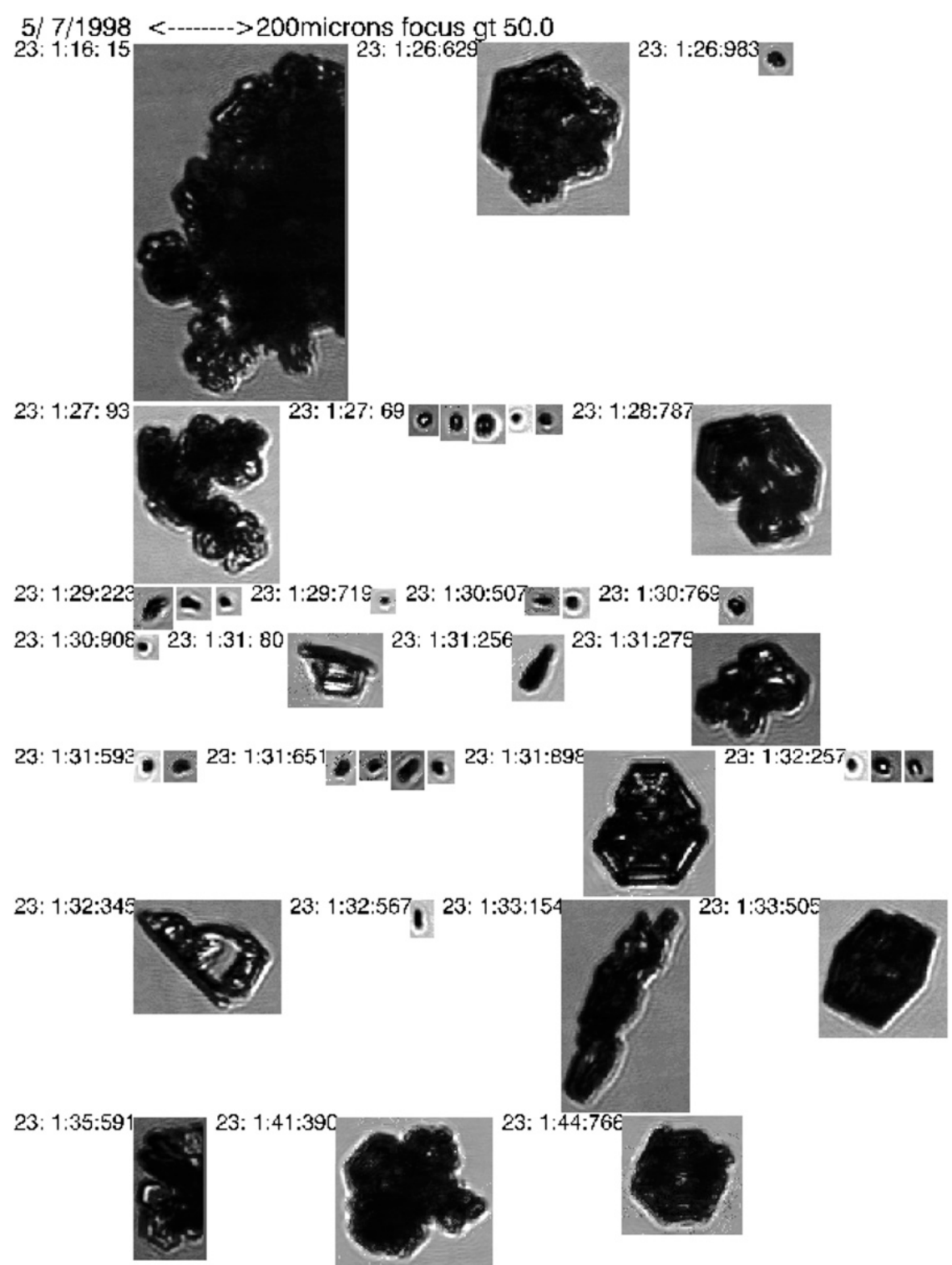

FIG. 4. Observed CPI images of ice crystals at 2301 UTC 7 May 1998 (aircraft below cloud at height of $\sim 200 \mathrm{~m}$; cf. Fig. 2), representative of ice sampled over 2200-2400 UTC. Length scale shown at top.

calculated from the individual in situ ice size distributions below cloud shown in Fig. 3 (all particle sizes initially included). Following the method described by van Diedenhoven et al. (2009), measured ice particle size distributions were averaged over 30 -s time periods, each mass-dimensional relation assumed for particles with $D>150 \mu \mathrm{m}$ (smaller particles assumed spherical), and reflectivities calculated using the QuickBeam package (Haynes et al. 2007). Comparison with the available below-cloud MMCR reflectivity measurements in the same time ranges (as a proxy for the same locations) indicates that assuming large particles are radiating assemblages of plates results in calculated reflectivities that agree best with observations (Fig. 5). Particles of $D<200 \mu \mathrm{m}$ do not contribute significantly (Fig. 5d). We do not consider this test particularly robust owing to the variability of MMCR reflectivity with time and the relatively sparse aircraft sampling. Nonetheless, owing to a lack of other constraints, we assume radiating plates to represent large ice, adopt the ad hoc areadimensional relationship proposed by Mitchell (1996), and perform sensitivity tests below.

The relationship of aspect ratio to maximum dimension has not received as much attention as mass and 
TABLE 1. Mass- and area-dimensional power laws used in simulations and radar reflectivity calculations.

\begin{tabular}{|c|c|c|c|c|c|c|}
\hline Habit & $D(\mathrm{~cm})^{\mathrm{a}}$ & $a^{\mathrm{b}}$ & $b^{\mathrm{b}}$ & $c^{\mathrm{b}}$ & $d^{\mathrm{b}}$ & Source ${ }^{c}$ \\
\hline Spheres & $0.0002-0.0005$ & 0.48014 & 3.00 & 0.78540 & 2.00 & - \\
\hline Transitional & $0.0005-0.012$ & 0.02306 & 2.61 & 0.17596 & 1.82 & - \\
\hline Radiating assemblages of plates & $>0.012$ & 0.00240 & 2.1 & 0.22850 & 1.88 & $\begin{array}{l}\text { LH74, MZP90, } \\
\text { M96, BL06 }\end{array}$ \\
\hline $\begin{array}{l}\text { Aggregates of unrimed radiating } \\
\text { assemblages of plates, side planes, } \\
\text { bullets, and columns }\end{array}$ & $>0.012$ & 0.00294 & 1.9 & 0.22850 & 1.88 & LH74, M96 \\
\hline \multirow[t]{2}{*}{ Plates with sectorlike branches } & $0.001-0.016$ & 0.00614 & 2.42 & 0.24 & 1.85 & M96 \\
\hline & $>0.016$ & 0.00142 & 2.02 & 0.55 & 1.97 & M96 \\
\hline Hexagonal plates & $>0.012$ & 0.00739 & 2.45 & 0.65 & 2.00 & M96 \\
\hline
\end{tabular}

${ }^{\text {a }}$ Range of maximum crystal dimension $D$ over which relationships are applied piecewise in simulations. Ranges shown for spheres and transitional properties (see section 3c) are those used when the largest ice crystals are radiating assemblages of plates. When the largest crystals are aggregates, the properties of spheres are applied over $0.0002-0.012 \mathrm{~cm}$. When the largest crystals are sectored plates, the properties of spheres are applied over $0.0002-0.001 \mathrm{~cm}$ and the two consecutive relations shown are then applied. Hexagonal plates are used only in radar reflectivity calculations (cf. section $4 \mathrm{~d}$ ).

${ }^{\mathrm{b}}$ Values of $a, b, c$, and $d$ in mass- and area-dimensional power laws $m=a D^{b}$ and $A=c D^{d}$, where $m$ is mass in grams, $D$ is maximum dimension in centimeters, and $A$ is projected area in centimeters squared.

${ }^{\mathrm{c}}$ LH74 = Locatelli and Hobbs (1974), MZP90 = Mitchell et al. (1990), M96 = Mitchell (1996), BL06 = Baker and Lawson (2006).

area. Based on an analysis of aspect ratio using CPI images collected in Arctic clouds in the $-15^{\circ}$ to $-20^{\circ} \mathrm{C}$ range (Korolev and Isaac 2003), we assume that the aspect ratio decreases linearly from 1.0 to 0.6 over a maximum dimension range of 5-120 $\mu \mathrm{m}$ and remains constant at larger sizes. Aspect ratio primarily influences ice fall speed and capacitance (see sensitivity tests in section 4d).

\section{d. Ice formation}

Since all ice crystals are present in the boundary layer temperature range of $-16^{\circ}$ to $-20^{\circ} \mathrm{C}$ and no ice was observed to be seeding the cloud from above, we assume that all primary ice nucleation proceeds heterogeneously. We take two approaches to represent heterogeneous IN activation. First, we follow the simplified diagnostic approach specified in the GCSS SHEBA case. The IN are activated as ice crystals if ice supersaturation exceeds $5 \%$ and are added to each grid cell such that the sum of ice crystals and IN never falls below the initial concentration of IN. A diagnostic approach was selected for the intercomparison based on results of the 10 October M-PACE model intercomparison, in which predicted ice crystal number concentrations ranged over five orders of magnitude, and it was therefore recommended that future studies constrain the treatment of ice nucleation and ice crystal number concentration (Klein et al. 2009). However, since ice crystal number concentration is itself highly uncertain, as are virtually all details of IN activity, this simplified approach is based on the suggestion that ice concentrations are roughly equal to overlying IN concentrations in this cloud type (Prenni et al. 2007). A general consequence of the diagnostic approach is that any IN consumption is compensated by an unlimited source of IN replenishment (e.g., Harrington and Olsson 2001).

We alternatively take a prognostic approach that accounts for IN sources, consumption, and transport (Fridlind et al. 2007). A spectrum of IN in each model grid cell is tracked in an array that ranges from least to most easily nucleated. Each array member contains IN that could be activated in any of the four commonly accepted modes: deposition, condensation, immersion, and contact (e.g., Pruppacher and Klett 1997). To calculate the rate of scavenging in the contact mode, all IN are assumed to be $0.5 \mu \mathrm{m}$ in diameter, the mean effective dimension observed during SHEBA (Rogers et al. 2001). We assume that sublimated ice crystals yield IN that are preactivated (e.g., Roberts and Hallett 1968; Knopf and Koop 2006) and therefore in the array member that is easiest to nucleate, but alternatively assuming no IN regeneration from sublimated crystals changes results negligibly since the air is saturated with respect to ice nearly to the surface in this case. Generic IN activation properties are assumed (Fridlind et al. 2007, their Table 1); they are not readily obtained from CFDC measurements because the instrument is not designed to distinguish between modes of activation and high spatial variability is commonly encountered during instrument scans over operating conditions in-flight (e.g., Rogers et al. 2001; Prenni et al. 2007). To represent observed conditions in this study, we initialize $N_{\text {IN }}$ to $1.7 \mathrm{~L}^{-1}$ based on the analysis of CFDC measurements conducted for the GCSS SHEBA case. Given the generic IN activation properties (e.g., IN availability increases linearly in the condensation mode over the temperature range $-8^{\circ}$ to $-22^{\circ} \mathrm{C}$ ), all $1.7 \mathrm{~L}^{-1}$ are accessible under boundary 

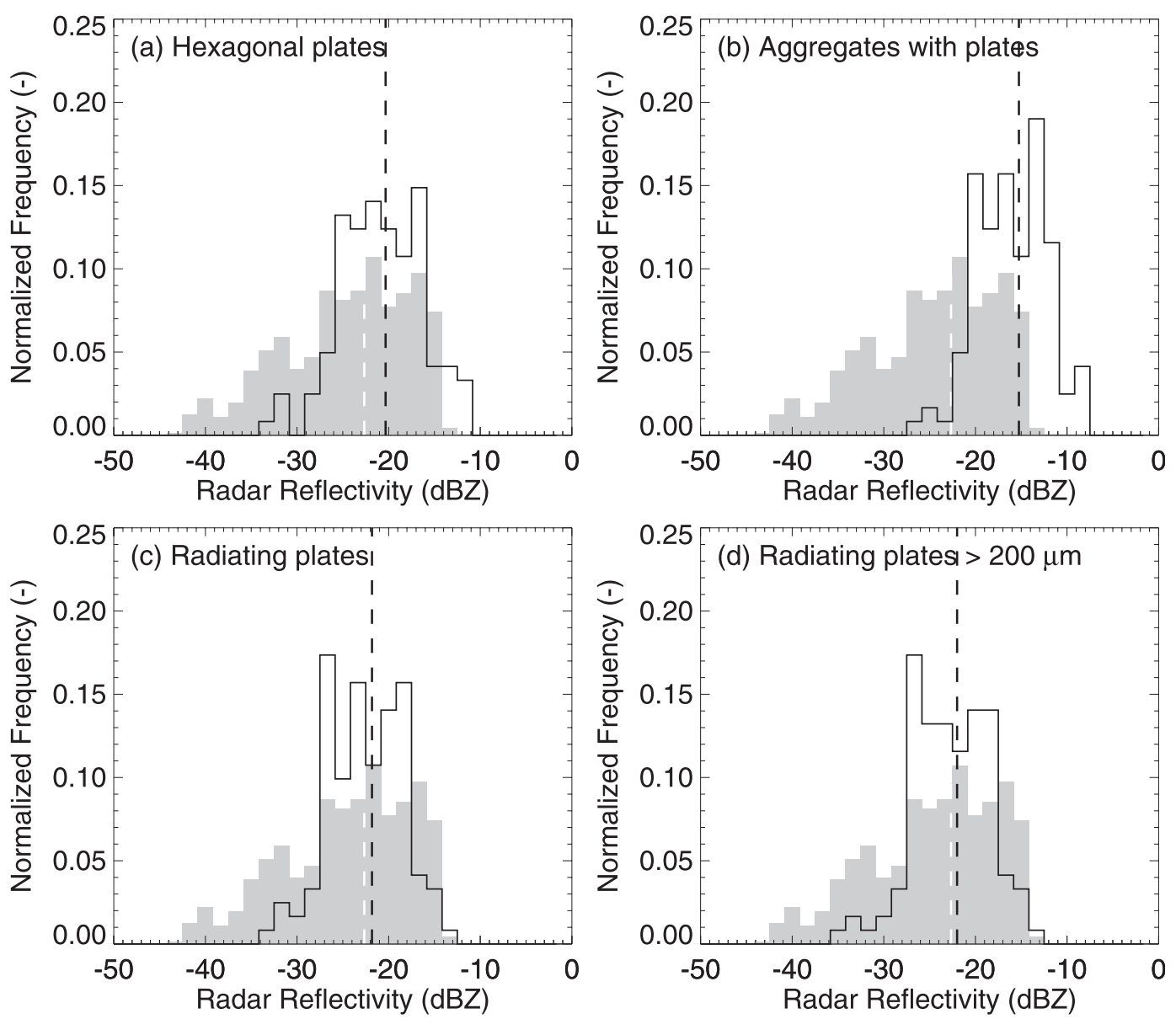

FIG. 5. Observed and calculated radar reflectivities. MMCR reflectivity observed between the surface and cloud base (180-280 m) during measurement of in situ size distributions over 2200-2400 UTC 7 May 1998 (shaded with median in dashed white line). Radar reflectivities calculated from size distributions observed in situ use varying massdimensional relations (solid lines with median in dashed black line; see section $3 \mathrm{c}$ and Table 1).

layer conditions in two modes (deposition and contact). For sensitivity tests in which all IN operate in only one mode at a time, the condensation mode temperature range is limited to $-8^{\circ}$ to $-19^{\circ} \mathrm{C}$ and the immersion mode temperature range is limited to $-10^{\circ}$ to $-19^{\circ} \mathrm{C}$; this guarantees that all IN can be activated in each mode independently under in-cloud conditions.

No well-established ice multiplication processes appear capable of significant secondary ice production under the observed conditions. Since liquid water content is small and was found only at temperatures colder than $-18^{\circ} \mathrm{C}$, Hallett-Mossop rime splintering is not active (Heymsfield and Mossop 1984). Shattering of drops larger than $50 \mu \mathrm{m}$ in diameter is included as described by Fridlind et al. (2007), but the simulated number concentration of such large drops is too small to be relevant. Simulated ice splinter production via ice-ice collisions is found to be insubstantial here when adopting an upper limit on the likely rate using the Vardiman (1978) parameterization as described in Fridlind et al. (2007), although this may not represent the maximum possible source because the unknown degree of ice crystal fall speed diversity is underestimated by choosing a single set of properties for each ice mass bin. Aside we note that such fall speed diversity was also neglected in our simulations of the 10 October M-PACE case (Fridlind et al. 2007), where observations indicated the coexistence of rimed and dendritic ice types likely more conducive to such multiplication (cf. Vardiman 1978; Yano and Phillips 2011).

\section{e. Radiative transfer}

Radiative transfer in 44 wavelength bins is computed independently for each column every $60 \mathrm{~s}$ using a twostream model (Toon et al. 1989) in which the water vapor continuum absorption has been modified (Clough et al. 1989). Particle scattering and absorption coefficients are computed from Lorenz-Mie theory (Toon and Ackerman 
1981). Since longwave fluxes outside of the $4.5-62-\mu \mathrm{m}$ wavelength range are not rigorously included (their impact on simulations is negligible), we account for their contribution when comparing with measurements by adding $6.7 \mathrm{~W} \mathrm{~m}^{-2}$ (the average flux in that wavelength range under simulated conditions). For radiative transfer, ice is treated as spherical with diameter equal to maximum dimension; this will be improved in future model development, but is sufficient for this case since ice has little impact on radiative fluxes (see also Zuidema et al. 2005).

\section{Results}

\section{a. Model setup}

We initialize model thermodynamic profiles, surface conditions, and top-of-model downwelling radiative fluxes, and apply large-scale tendencies over the 4-h simulation duration based on our adjustment of the GCSS SHEBA case (see appendix). As in the baseline GCSS SHEBA case, $N_{\mathrm{IN}}$ is initialized to $1.7 \mathrm{~L}^{-1}$ and aerosol are initialized in two lognormal modes with geometric standard deviations of 2.04 and 2.5, geometric radii of 0.052 and $1.3 \mu \mathrm{m}$, and number concentrations of 350 and $2 \mathrm{~cm}^{-3}$, respectively. When ice is not present, these conditions lead to a cloud-topped boundary layer with steady liquid water path (LWP; see appendix).

\section{b. Diagnostic versus prognostic IN}

To introduce ice formation, we first use a diagnostic treatment of IN, which sustains the ice crystal concentration continuously at the initial $N_{\mathrm{IN}}$ of $1.7 \mathrm{~L}^{-1}$ (see section $3 \mathrm{~d}$ ). This results in complete desiccation of the initial liquid water cloud within the 4-h simulation time (Fig. 6, solid lines). We next use a prognostic treatment of IN, which accounts for IN consumption (Fig. 6, dotted lines). After initial boundary layer IN are quickly consumed, the only (weak) source of new IN is then cloudtop entrainment, and LWP reaches a quasi-equilibrium state (defined throughout as sustaining an $e$-folding lifetime of at least 10-h during hours 3-4; see appendix). Most IN are consumed instantly, and once boundary layer turbulence develops, the remainder are consumed within minutes. Since the boundary layer is saturated with respect to ice in this case, sublimation is negligible and activated IN are removed from the boundary layer when ice crystals sediment.

If the simulation with prognostic IN is repeated with all IN available in only one mode at a time (see section $3 d$ ), then consumption remains similarly efficient for all modes except contact, as discussed further below. The IN are activated at a much slower rate in the contact mode
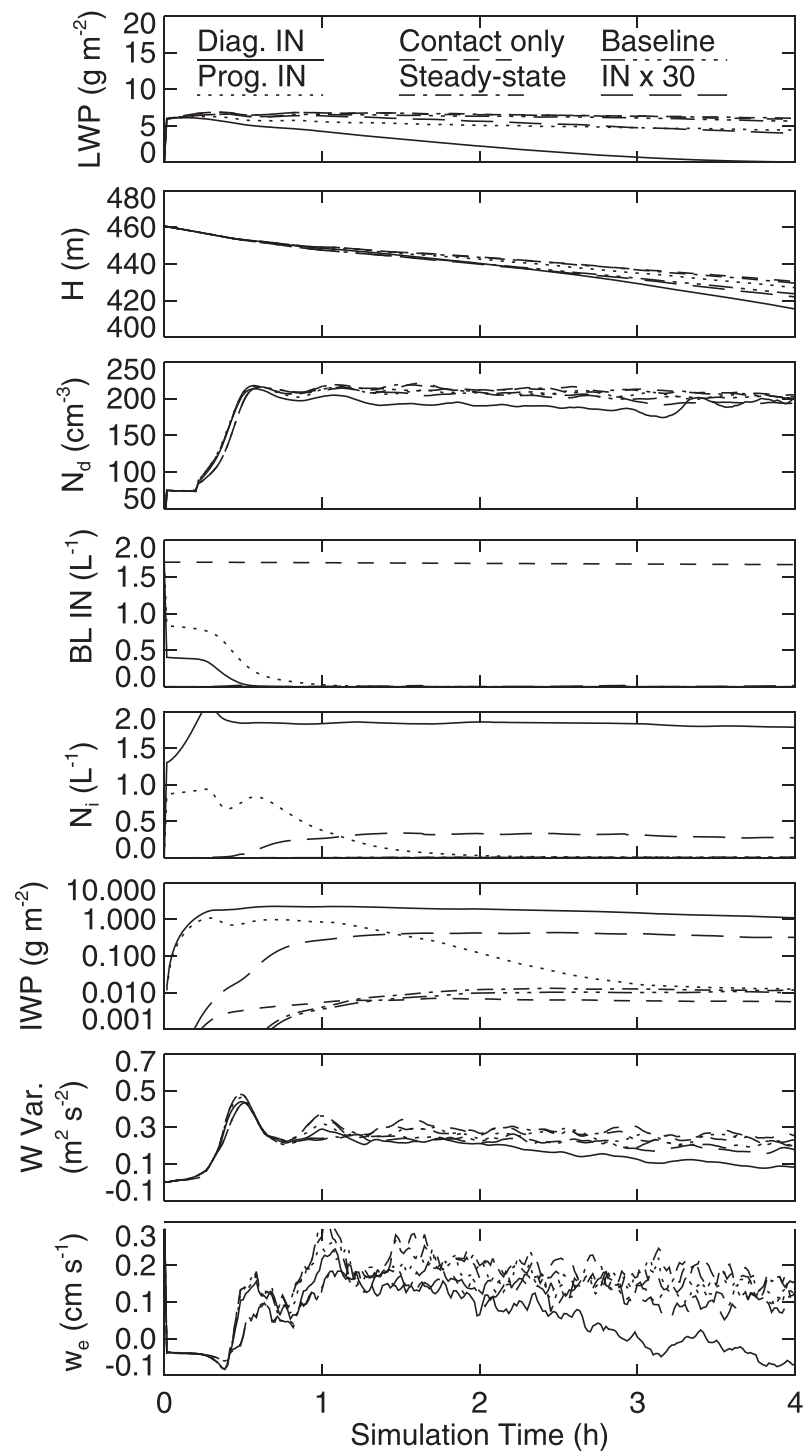

FIG. 6. Simulated domain-mean LWP, boundary layer depth $H$ (defined by mean elevation where liquid water potential temperature is $258 \mathrm{~K}$ ), droplet number concentration $N_{d}$ (averaged over all grid cells with liquid water mixing ratio $>10^{-3} \mathrm{~g} \mathrm{~kg}^{-1}$ ), boundary layer (BL) IN and ice crystals $N_{i}$ averaged over $H$, domain-mean ice water path (IWP), domain-maximum variance of vertical wind speed $W$, and cloud-top entrainment rate $w_{e}$ (computed as $d H / d t$ plus large-scale subsidence rate at $H$ ). Simulations listed in Table 2: diagnostic IN (solid lines), prognostic IN (dotted lines), contact IN only (short dashed lines), steady-state prognostic IN (dash-dotted lines), baseline (dash-triple-dotted lines), and IN $\times 30$ (long dashed lines). Boundary layer IN and $N_{i}$ remain small at all times in some simulations.

owing to inefficient scavenging of IN by droplets, and are scarcely consumed from the boundary layer within the 4-h simulation time (Fig. 6, short dashed lines). Since it is not expected that IN active in the contact mode are inactive in other modes (e.g., Prenni et al. 2009), and we 
TABLE 2. Simulations with size-resolved mixed-phase microphysics.

\begin{tabular}{|c|c|c|c|c|c|}
\hline Simulation & $\begin{array}{c}\text { Case } \\
\text { specification }^{\mathrm{a}}\end{array}$ & IN scheme & $\begin{array}{c}\text { Initial } \\
\text { above-cloud } N_{\mathrm{IN}}\left(\mathrm{L}^{-1}\right)\end{array}$ & $\begin{array}{c}\text { Initial } \\
\text { boundary layer } N_{\mathrm{IN}}\left(\mathrm{L}^{-1}\right)^{\mathrm{b}}\end{array}$ & Ice crystal habit $^{\mathrm{c}}$ \\
\hline Diagnostic IN & A & Diagnostic & 1.7 & 1.7 & Radiating plates \\
\hline Prognostic IN & A & Prognostic & 1.7 & 1.7 & Radiating plates \\
\hline Contact IN only & A & Prognostic & 1.7 & 1.7 & Radiating plates \\
\hline $\begin{array}{l}\text { Steady-state } \\
\text { prognostic IN }\end{array}$ & A & Prognostic & 1.7 & 0 & Radiating plates \\
\hline Baseline & $\mathrm{B}$ & Prognostic & 1.7 & 0 & Radiating plates \\
\hline IN $\times 30$ & $\mathrm{~B}$ & Prognostic & 51 & 0 & Radiating plates \\
\hline Deposition IN only & $\mathrm{B}$ & Prognostic & 51 & 0 & Radiating plates \\
\hline Condensation IN only & $\mathrm{B}$ & Prognostic & 51 & 0 & Radiating plates \\
\hline Immersion IN only & $\mathrm{B}$ & Prognostic & 51 & 0 & Radiating plates \\
\hline Decreased capacitance & $\mathrm{B}$ & Prognostic & 51 & 0 & Radiating plates \\
\hline Aggregates & $\mathrm{B}$ & Prognostic & 51 & 0 & $\begin{array}{l}\text { Aggregates with } \\
\text { plates }\end{array}$ \\
\hline Plates & $\mathrm{B}$ & Prognostic & 51 & 0 & Sectored plates \\
\hline Modified diagnostic IN & $\mathrm{B}$ & Diagnostic & 0.29 & 0.29 & Radiating plates \\
\hline GCSS submission & $\mathrm{G}$ & Diagnostic & 1.7 & 1.7 & Radiating plates \\
\hline
\end{tabular}

${ }^{a} \mathrm{G}=$ original GCSS SHEBA case specification for 1200-2400 UTC (Morrison et al. 2011), A = adjusted case specification for 20002400 UTC (see appendix), B = baseline case specification with increased downwelling longwave radiation and moisture convergence (see section $4 \mathrm{c}$ ).

${ }^{\mathrm{b}}$ Initializing boundary layer $N_{\text {IN }}$ to zero reduces spinup associated with starting far from quasi-equilibrium (see section $4 \mathrm{~b}$ ).

${ }^{\mathrm{c}}$ Habit of ice crystals with largest maximum dimensions; smaller particles spherical or transitional (see section $3 \mathrm{c}$ and Table 1).

have no evidence for an independent reservoir of contact IN, we assume that any contact IN can act in at least one other mode and are therefore activated rapidly. Based on the first published simulations that apply a prognostic approach to ice nucleation in mixedphase boundary layer clouds, Harrington and Olsson (2001) also describe rapid IN depletion. Others have reported it in simulations of the 10 October M-PACE case (Fridlind et al. 2007; Fan et al. 2009; Avramov and Harrington 2010) and under SHEBA conditions (Morrison et al. 2005).

Whereas all liquid water was consumed when treating IN diagnostically, desiccation is by contrast limited when treating IN prognostically, despite an initial burst of ice formation that does not persist when accounting for IN depletion. To eliminate the initial burst of ice formation and more quickly reach quasi-equilibrium ice water path (see also Fridlind et al. 2007), we next initialize IN in the boundary layer to zero, leaving only IN above the boundary layer at the background value of $1.7 \mathrm{~L}^{-1}$ (Fig. 6, dash-dotted lines). We refer to this as a steady-state initialization approach (since boundary layer IN concentration is initialized close to its very low quasi-equilibrium value), and use it in the remaining simulations with prognostic IN (Table 2).

\section{c. IN insufficient to explain observed ice}

The simulated droplet number size distributions match in-cloud observations quite well in the simulation with steady-state prognostic IN, but the predicted number concentration of ice is too low by more than an order of magnitude at all sizes (Fig. 7a). Thus, $N_{\text {IN }}$ measured above cloud appears insufficient to explain observed ice crystal numbers. Using the QuickBeam package (Haynes et al. 2007) to calculate $35-\mathrm{GHz}$ reflectivities and mean Doppler velocities below cloud from simulated ice crystal size distributions and vertical wind speeds at degraded vertical model resolution to match MMCR observations, as described by van Diedenhoven et al. (2009), we find that median simulated radar reflectivity is also greater than $10 \mathrm{dBZ}$ lower than observed (Fig. 8a). This discrepancy is consistent with the model underestimation of ice number concentration over all observed sizes. Although the median of mean Doppler velocities is underestimated by about $10 \mathrm{~cm} \mathrm{~s}^{-1}$ relative to the observed median of $50 \mathrm{~cm} \mathrm{~s}^{-1}$ (Fig. 8b), it is estimated that measured Doppler velocities are biased high by about $10 \mathrm{~cm} \mathrm{~s}^{-1}$ based on the shipborne radar tilt and boundary layer winds during 2000-2400 UTC. Thus agreement of the observed and simulated medians appears close, but the simulated distribution of mean Doppler velocities is broader than observed.

The overly broad distribution of Doppler velocities suggests that simulated boundary layer dynamics may be too strong. Given the limitations of our modeling approach and the constraints imposed by observed surface and sounding measurements, we are left with few relevant degrees of freedom. If the downwelling longwave radiative flux specified at $1-\mathrm{km}$ height, which is not directly constrained by observations in the GCSS 

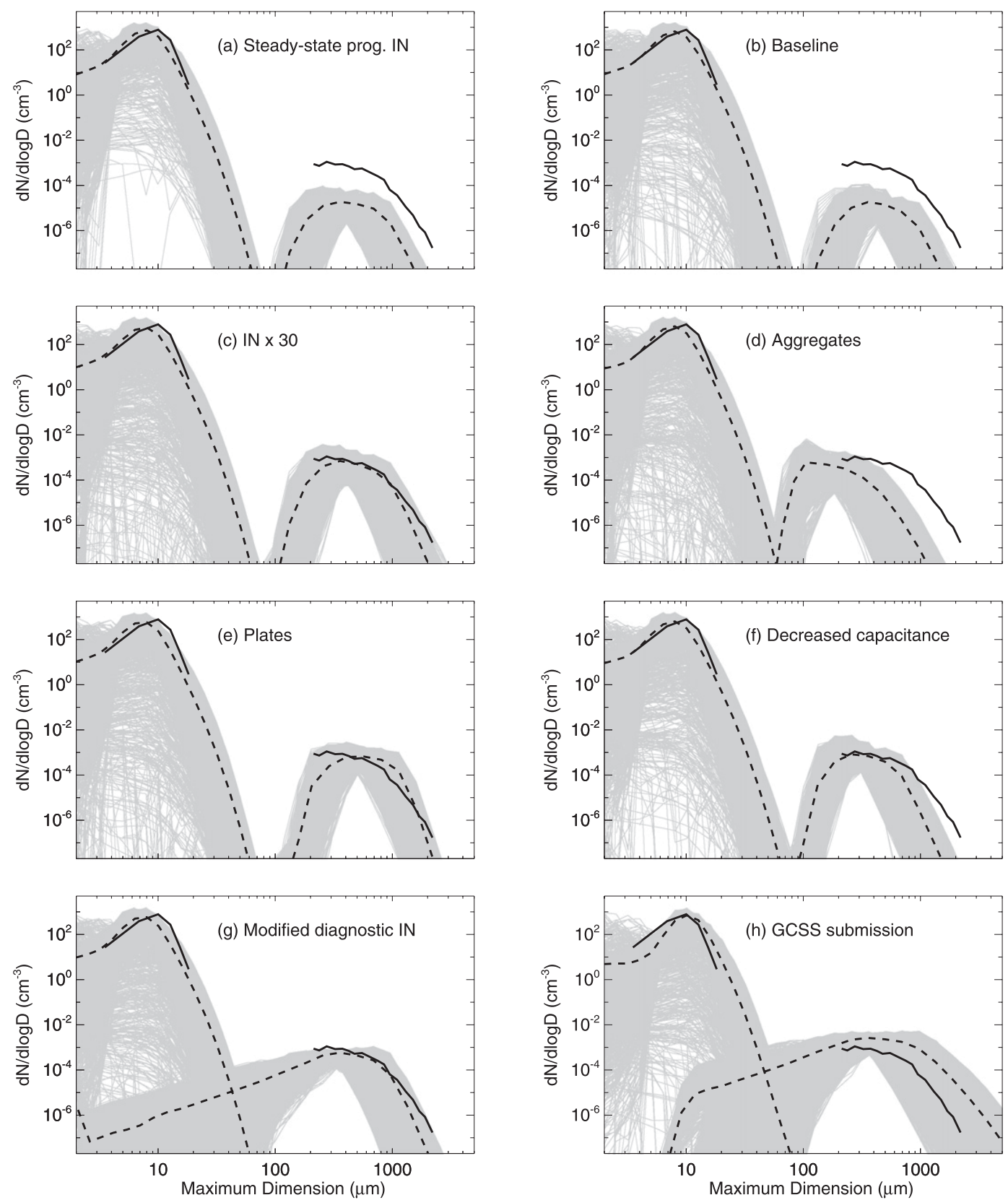

FIG. 7. Observed and simulated droplet and ice particle size distributions. Observed mean size distributions measured with FSSP and 2D-C probes during 2229-2359 UTC 7 May 1998 (solid black lines, as in Fig. 3) at reported aircraft altitudes of 310-430 m (drops) and below $280 \mathrm{~m}$ (ice) are compared with simulated size distributions of drops at $310-430 \mathrm{~m}$ and ice below $280 \mathrm{~m}$ (gray lines, black dashed line is mean). Simulations listed in Table 2: (a) steadystate prognostic IN, (b) baseline, (c) IN $\times 30$, (d) aggregates, (e) plates, (f) decreased capacitance, $(\mathrm{g})$ modified diagnostic IN, and (h) GCSS submission. Simulations are sampled at $12 \mathrm{~h}$ (GCSS submission, corresponding to 2400 UTC) or $3 \mathrm{~h}$ (all others, corresponding to 2300 UTC).

SHEBA case, is increased by $15 \mathrm{~W} \mathrm{~m}^{-2}$, then cloudtop radiative cooling and entrainment are reduced. If large-scale horizontal advective flux convergence of the water vapor mixing ratio $q_{v}$ is increased to a vertically uniform rate of $0.09 \mathrm{~g} \mathrm{~kg}^{-1} \mathrm{day}^{-1}$ to maintain quasi-equilibrium LWP, simulations remain consistent with observations (see appendix). These changes result in the mean Doppler velocities agreeing better with measurements (Fig. 8d), with little associated impact on reflectivity (Fig. 8c versus Fig. 8a) or ice size 

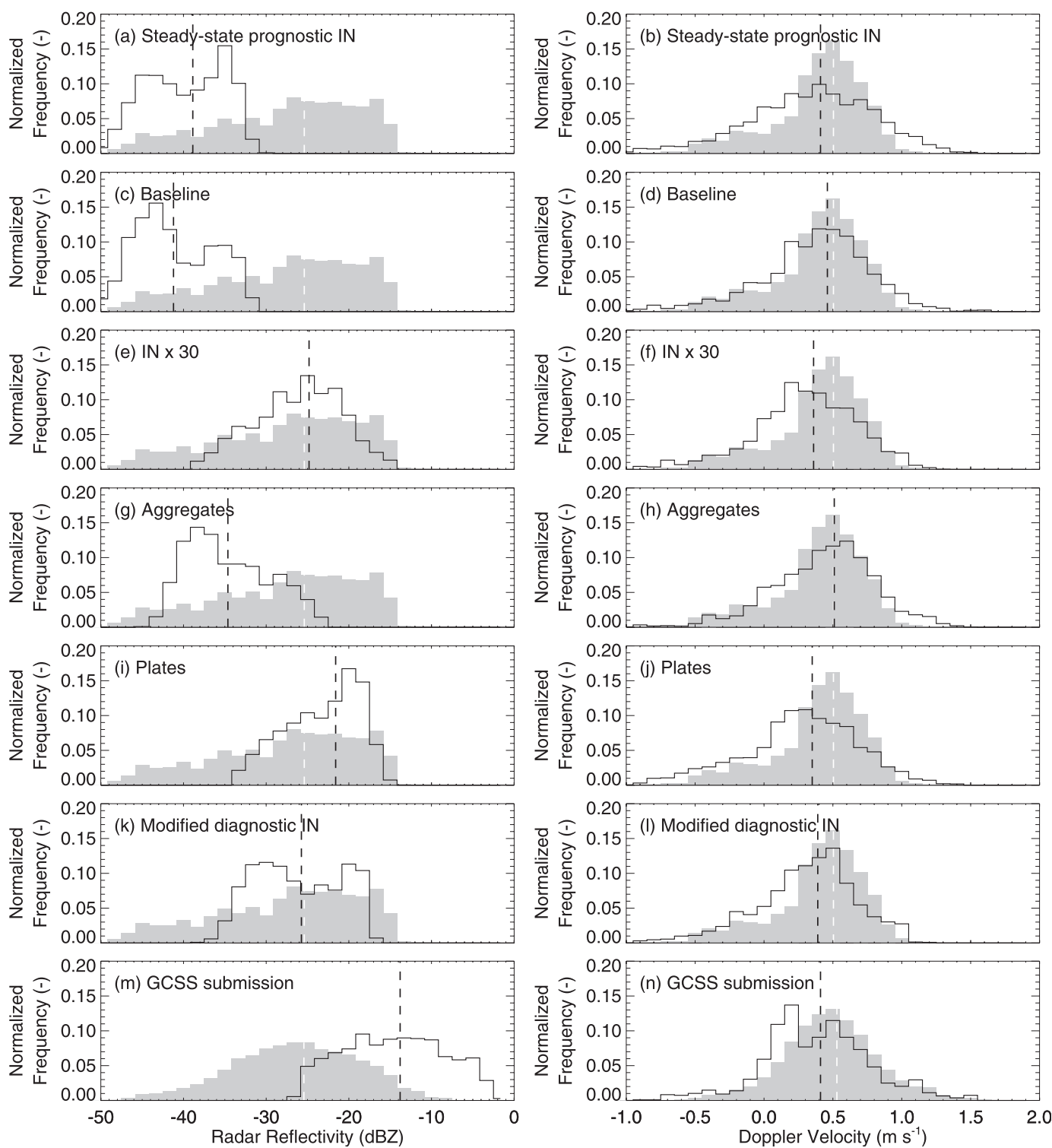

FIG. 8. Observed and simulated histograms of radar reflectivity and mean Doppler velocity below cloud base (180$280 \mathrm{~m}$ ). Observed MMCR reflectivity and Doppler velocity during (a)-(1) 2200-2400 UTC and (m),(n) 12002400 UTC 7 May 1998 (shaded, dashed white line is median). Simulations listed in Table 2: (a),(b) steady-state prognostic IN, (c),(d) baseline, (e),(f) IN $\times 30$, (g), (h) aggregates, (i),(j) plates, (k),(l) modified diagnostic IN, and (m),(n) GCSS submission. Simulations are randomly sampled (solid black line, dashed black line is median) over 2-12 h (GCSS submission, corresponding to 1400-2400 UTC) or 3-4 h (all others, corresponding to 2300-2400 UTC). MMCR Doppler velocity is likely biased high by $\sim 10 \mathrm{~cm} \mathrm{~s}^{-1}$ based on radar tilt and boundary layer wind speeds during 2000-2400 UTC.

distribution (Fig. 7b versus Fig. 7a). We therefore adopt these modifications for our baseline simulation (denoted as case specification B in Table 2; aside we note that retaining case specification A throughout would not alter our conclusions). Finally, considering this baseline simulation, we note that the simulated reflectivity is dominated by particles of $500-1000 \mu \mathrm{m}$ in maximum dimension (Fig. 9a).

\section{d. Additional IN required to match observations}

Ice properties are quite uniform vertically in the baseline simulation (Fig. 10), as commonly observed (e.g., McFarquhar et al. 2007, 2011), including the total concentration of ice crystals $N_{i}$, to which particles smaller than $200 \mu \mathrm{m}$ contribute little (cf. Fig. 9a). In addition, $N_{i}$ below cloud, which is representative of the whole 

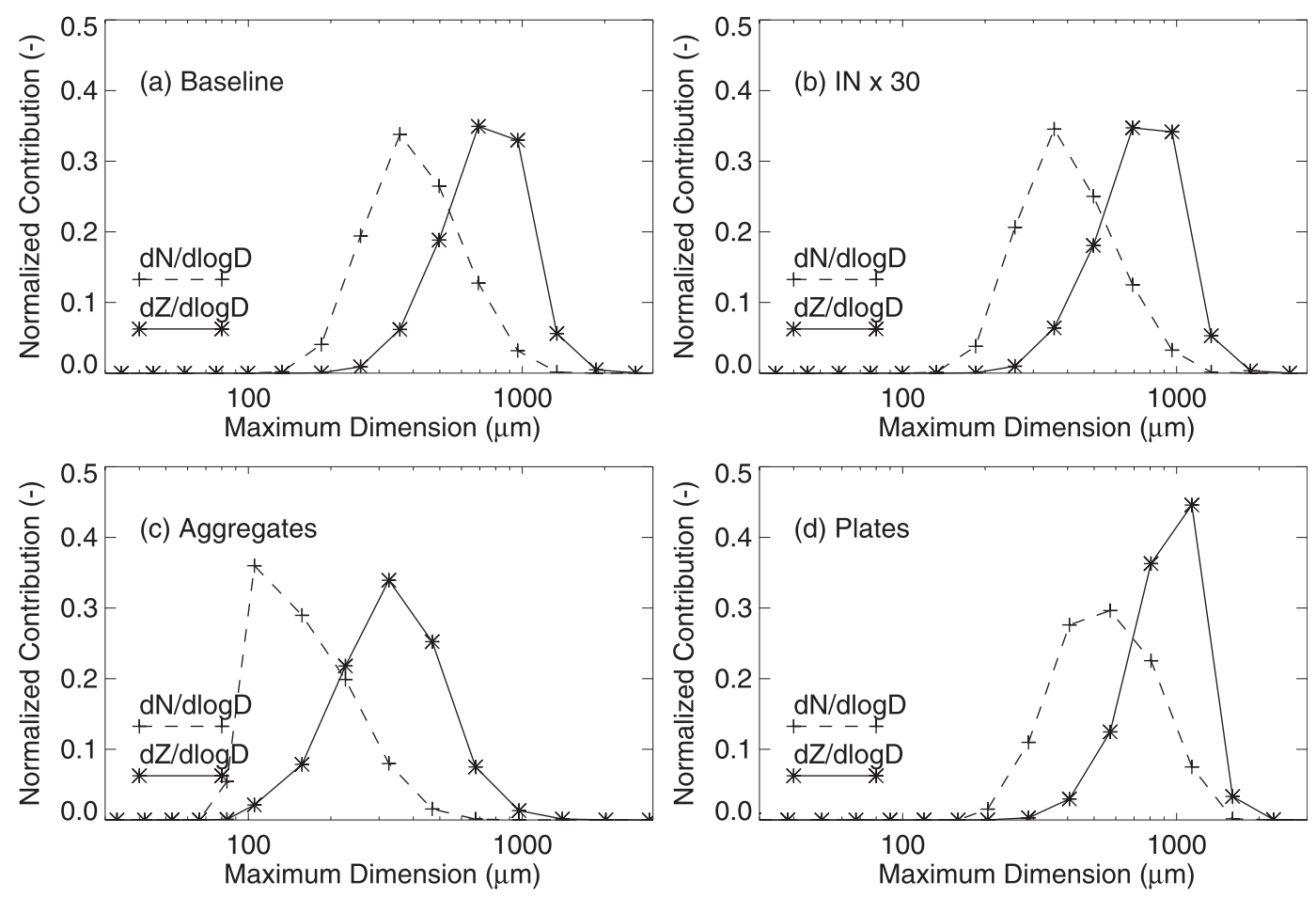

FIG. 9. Simulated normalized contribution of ice to total number concentration $d N / d \log D$ and radar reflectivity $d Z / d \log D$ for the corresponding mean ice size distributions shown in Fig. 7.

boundary layer, is about 200 times smaller than the overlying $N_{\text {IN }}$ of $1.7 \mathrm{~L}^{-1}$ (Table 3 ). To better match the mean observed ice crystal size distribution, we find that we need to initialize $N_{\text {IN }}$ to a value 30 times greater than $1.7 \mathrm{~L}^{-1}(\mathrm{IN} \times 30$ in Fig. $7 \mathrm{c}$ and Tables 2 and 3$)$. This also improves agreement with radar reflectivity (Fig. 8e), although the simulated range of radar reflectivity remains somewhat narrow and mean Doppler velocities somewhat slow (Figs. 8e and 8f), as discussed further below. When $N_{\text {IN }}$ is thus increased, ice crystal number concentration increases roughly linearly at all sizes, such that the normalized contributions of each particle size to number concentration and reflectivity remain nearly constant (Fig. 9b versus Fig. 9a). Despite the greater than tenfold increase in $N_{i}$, LWP develops only a modest downward trend and droplet concentration is negligibly impacted (Fig. 6, long dashed lines).

The somewhat worsened agreement of simulated Doppler velocities with measurements prompts consideration of sensitivity to ice crystal habit, fall speed, and growth rate. Aggregates with plates fall faster than the radiating assemblages of plates assumed thus far (Fig. 11) and these two crystal types may be difficult to distinguish in some CPI images (see Fig. 4). Singular hexagonal plates fall slower and are relatively common in CPI images, but because their fall speeds are very similar to radiating plates over $D$ of $100-400 \mu \mathrm{m}$, we use plates with sectorlike branches (sectored plates, also seen in CPI images) for a second sensitivity test. Assuming aggregates, simulated ice crystal size distributions shift to smaller sizes (Fig. 7d), radar reflectivity is correspondingly underestimated by about $10 \mathrm{dBZ}$ (Fig. 8g), and mean Doppler velocities increase (Fig. 8h). By contrast, assuming sectored plates has a more modest, opposite effect (Figs. 7e and 8i,j). Size-resolved contributions to radar reflectivity shift accordingly (Figs. 9c,d). In general, given faster-falling crystals, more IN aloft would be required to match observed ice size distributions and radar reflectivities.

We note that changes in the mode of IN activation have a lesser impact on our results than the foregoing changes in assumed ice habit (see Table 3), despite differences in the nucleated ice crystal size (e.g., $D=2 \mu \mathrm{m}$ assumed for nucleated deposition IN versus preferentially large droplet size for nucleated immersion IN); when IN become available under cloud-top conditions, they are efficiently consumed in any mode except contact, and they grow rapidly to $D>100 \mu \mathrm{m}$ regardless of initial size (cf. Fig. 9). Reducing the ratio of capacitance to maximum dimension to $0.35-0.25$ for all crystal sizes (see section $3 b$ ) also has a lesser impact on size distribution shape (Fig. 7f versus Fig. 7c). However, the treatment of vapor growth rates for the diversity of radiating plates and other ice particle shapes seen in CPI 

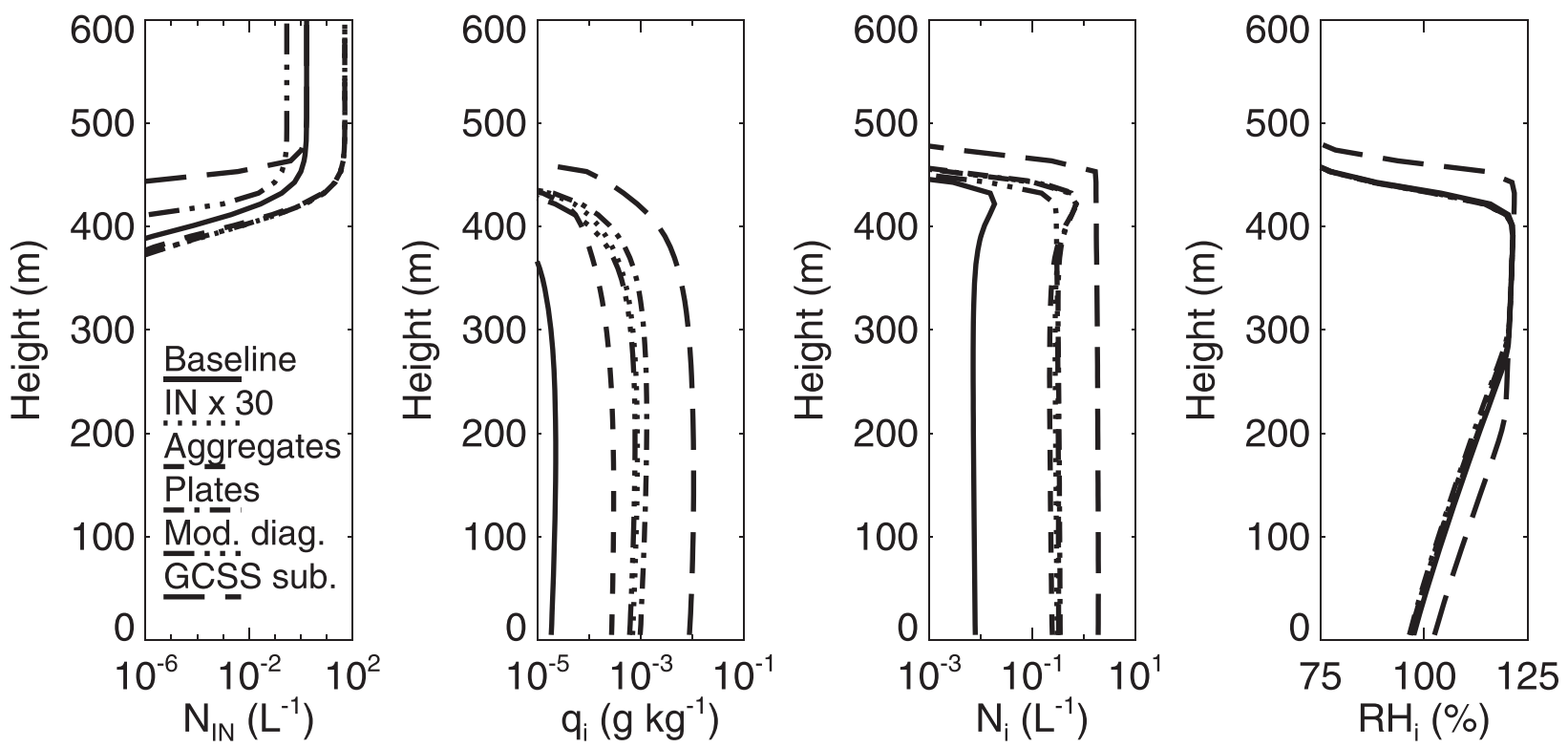

FIG. 10. Simulated profiles of domain-average ice nucleus number concentration $N_{\mathrm{IN}}$, ice mass mixing ratio $q_{i}$, total ice crystal number concentration $N_{i}$, and relative humidity over ice $\left(\mathrm{RH}_{i}\right)$ averaged over last $2 \mathrm{~h}$ of simulation time (corresponding to 2200-2400 UTC). Simulations listed in Table 2: baseline (solid lines), IN $\times 30$ (dotted lines), aggregates (short dashed lines), plates (dash-dotted lines), modified diagnostic IN (dash-triple-dotted lines), and GCSS submission (long dashed lines).

images is uncertain and should be considered further in future work.

The sensitivity of results to cloud-top entrainment rate $w_{e}$ should also be considered. In simulations, $w_{e}(\sim 0.1$ $\mathrm{cm} \mathrm{s}^{-1}$; see Table 3$)$ is computed as the rate of change of boundary layer depth $H\left(\sim-0.3 \mathrm{~cm} \mathrm{~s}^{-1}\right.$; see Fig. 6) plus the large-scale subsidence rate at cloud top $\left(\sim 0.4 \mathrm{~cm} \mathrm{~s}^{-1}\right.$; see appendix), which is poorly constrained by reanalysis fields. However, in order to account for observed ice at quasi-equilibrium with above-cloud $N_{\mathrm{IN}}$ of $1.7 \mathrm{~L}^{-1}, w_{e}$ would need to increase by a factor of 30 from about 0.1 to $3 \mathrm{~cm} \mathrm{~s}^{-1}$. It is difficult to reproduce relatively steady $H$ under low-LWP conditions with such a large $w_{e}$. For instance, if large-scale subsidence rate is increased by a factor of 2 and $q_{v}$ advective convergence increased sufficiently to maintain quasi-equilibrium LWP, then $H$ decreases by about $80 \mathrm{~m}$ over $4 \mathrm{~h}$ (not shown, compared with about $40 \mathrm{~m}$ in the baseline simulation and about $70 \mathrm{~m}$ estimated from radar measurements), $w_{e}$ is reduced by about $20 \%$, and more IN aloft would again be required

TABLE 3. Simulation results: ice nucleus number concentration above the boundary layer $N_{\mathrm{IN}}$, cloud-top entrainment rate $w_{e}$, mean number-weighted ice crystal fall speed at the surface $v_{f}$, ice crystal number concentration predicted by Eq. (3) $\left(N_{\text {IN }} w_{e} / v_{f}\right)$, ice crystal concentration $N_{i}$ and ice mass mixing ratio $q_{i}$ averaged below $280 \mathrm{~m}$ (representative of boundary layer values), and $N_{i} / N_{\text {IN. }}$ All values averaged over the last $2 \mathrm{~h}$ of simulation time (corresponding to 2200-2400 UTC) except $N_{\text {IN }}$, which is a model input (see Table 2).

\begin{tabular}{|c|c|c|c|c|c|c|c|}
\hline Simulation & $N_{\mathrm{IN}}\left(\mathrm{L}^{-1}\right)$ & $w_{e}\left(\mathrm{~cm} \mathrm{~s}^{-1}\right)$ & $v_{f}\left(\mathrm{~cm} \mathrm{~s}^{-1}\right)$ & $N_{\mathrm{IN}} w_{e} / v_{f}\left(\mathrm{~L}^{-1}\right)$ & $N_{i}\left(\mathrm{~L}^{-1}\right)$ & $q_{i}\left(\mathrm{mg} \mathrm{kg}^{-1}\right)$ & $N_{i} / N_{\text {IN }}(-)$ \\
\hline Steady-sate prognostic IN & 1.7 & 0.17 & 30.0 & 0.0096 & 0.0088 & 0.025 & 0.0052 \\
\hline Baseline & 1.7 & 0.13 & 31.0 & 0.0071 & 0.0074 & 0.021 & 0.0043 \\
\hline $\mathrm{IN} \times 30$ & 51.0 & 0.11 & 30.0 & 0.18 & 0.29 & 0.81 & 0.0057 \\
\hline Deposition IN only & 51.0 & 0.11 & 31.0 & 0.18 & 0.28 & 0.77 & 0.0055 \\
\hline Condensation IN only & 51.0 & 0.11 & 30.0 & 0.19 & 0.26 & 0.67 & 0.0051 \\
\hline Immersion IN only & 51.0 & 0.12 & 31.0 & 0.20 & 0.29 & 0.81 & 0.0057 \\
\hline Decreased capacitance & 51.0 & 0.12 & 26.0 & 0.24 & 0.35 & 0.55 & 0.0069 \\
\hline Aggregates & 51.0 & 0.12 & 38.0 & 0.16 & 0.23 & 0.28 & 0.0043 \\
\hline Plates & 51.0 & 0.12 & 25.0 & 0.24 & 0.33 & 1.2 & 0.0065 \\
\hline Modified diagnostic IN & $0.29 *$ & 0.12 & 27.0 & - & 0.32 & 0.72 & - \\
\hline GCSS submission & $1.7 *$ & 0.29 & 32.0 & - & 1.8 & 7.4 & - \\
\hline
\end{tabular}

* Small differences between diagnostic $N_{\text {IN }}$ and below-cloud mean $N_{i}$ attributable to boundary layer mixing conserving mixing ratio rather than concentration. 


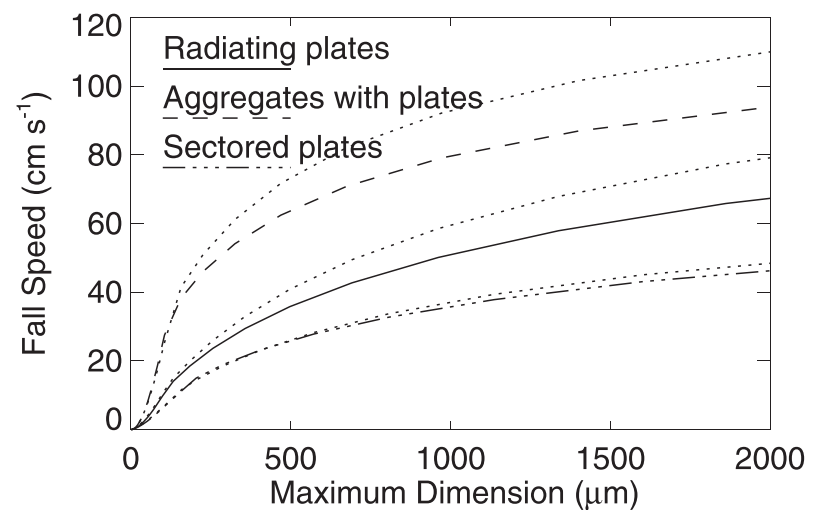

FIG. 11. Simulation ice particle fall speeds versus maximum dimension calculated at the surface per Böhm $(1989,1999)$ for radiating plates (baseline, solid curves), aggregates (dashed curves), and plates with sectorlike branches (dash-dotted curves). Using the same ice crystal properties (see Table 1), fall speeds calculated per Heymsfield and Westbrook (2010) are shown for comparison (dotted curves)

to match observations. We therefore believe that a factor of 30 increase in IN concentration likely errs on the low side required to explain the average in situ and remote sensing measurements within this modeling framework. Aside we note that even if local boundary layer depth were stationary, mesoscale gradients in boundary layer depth could exist that would not be captured with periodic boundary conditions (e.g., Avramov and Harrington 2010). Lacking reliable observations of regional boundary layer depth gradients, this possibility is not pursued here.

\section{e. Entrainment limitations on rapidly consumed IN}

In all simulations with prognostic IN, equilibrium $N_{i}$ is two orders of magnitude smaller than $N_{\text {IN }}$ overlying the boundary layer (see Table 3). To understand the processes controlling $N_{i} / N_{\text {IN }}$ in these simulations, it is useful to consider a simple mixed-layer model for $N_{i}$ in the cloud-topped boundary layer, using the framework developed by Lilly (1968). As described above, ice properties are quite uniform vertically, entrained IN are rapidly activated, no other ice formation process is active, and the sole fate of all ice crystals is sedimentation to the surface. For a boundary layer of depth $H$ entraining overlying air at a rate $w_{e}$, ice crystals are therefore added at a rate $w_{e} N_{\mathrm{IN}} / H$ and sedimented at a rate $v_{f} N_{i} / H$, where $v_{f}$ is the number-weighted ice crystal fall speed at the surface. Cloud-top entrainment of icefree air also dilutes $N_{i}$ at a rate $w_{e} N_{i} / H$. Neglecting large-scale horizontal advective tendencies and the vertical dependence of air density, the mixed-layer $N_{i}$ budget can then be expressed as

$$
H \frac{d N_{i}}{d t}=w_{e} N_{\mathrm{IN}}-\left(v_{f}+w_{e}\right) N_{i}
$$

For the simulated conditions, $w_{e} \ll v_{f}$ (see Table 3 ), and Eq. (1) can be simplified to

$$
H \frac{d N_{i}}{d t}=w_{e} N_{\mathrm{IN}}-v_{f} N_{i}
$$

Dividing the ice crystal reservoir $H N_{i}$ by its sink $v_{f} N_{i}$ gives an $e$-folding time scale $H / v_{f}$ of about 20-30 min on which $N_{i}$ relaxes toward its steady-state value

$$
N_{i}=N_{\mathrm{IN}} w_{e} / v_{f}
$$

Table 3 shows $N_{\mathrm{IN}}, w_{e}$, and $v_{f}$ averaged over hours 2-4 of simulation time (cf. Fig. 6), the solution to Eq. (3), $N_{i}$ averaged over hours 2-4 below cloud (representative of mean boundary layer values; cf. Fig. 10) and the ratio $N_{i} / N_{\text {IN }}$. Equation (3) reproduces $N_{i}$ to within $10 \%$ at the lower $N_{i}$ values and to within $30 \%-40 \%$ at the higher $N_{i}$ values, in all cases capturing the two orders of magnitude difference between $N_{i}$ and $N_{\text {IN }}$. Thus, $N_{i} / N_{\text {IN }} \ll 1$ since the supply of IN to the boundary layer is limited by a cloud-top entrainment rate that is much smaller than the number-weighted ice crystal fall speed.

Quasi-equilibrium $N_{i}$ can be reached in simulations because the 4-h simulation time is about 10 times greater than the $N_{i}$ relaxation time. However, the divergence of agreement between Eq. (3) and simulated $N_{i}$ at the higher $N_{i}$ values could be attributable to departure from quasi-equilibrium as desiccation increases (cf. Fig. 6) and cloud-top entrainment rate is reduced (cf. Table 3), consistent with ice loss rates that exceed supply rates in those simulations (Fig. 12). Equation (3) nonetheless explains the vast discrepancy between $N_{i}$ and $N_{\text {IN. }}$. In addition, when $N_{\text {IN }}$ increases, the ice crystal size distribution shape remains relatively unaffected as it is shifted upward to greater $N_{i}$ (equivalent to multiplying by a size-independent factor), as noted above. Therefore $v_{f}$ is relatively constant, which is associated with a characteristic size distribution of ice in the boundary layer and a linear scaling of boundary layer ice mass mixing ratio $q_{i}$ with $N_{i}$ (Fig. 12). As shown above, the characteristic size distribution depends strongly on habit (e.g., assuming aggregates rather than radiating plates reduces $q_{i}$ by more than half), consistent with results from other case studies (e.g., Morrison and Pinto 2006; Avramov and Harrington 2010).

\section{f. Modified diagnostic IN}

It is worthwhile to briefly compare our results with the GCSS SHEBA model intercomparison study (Morrison 

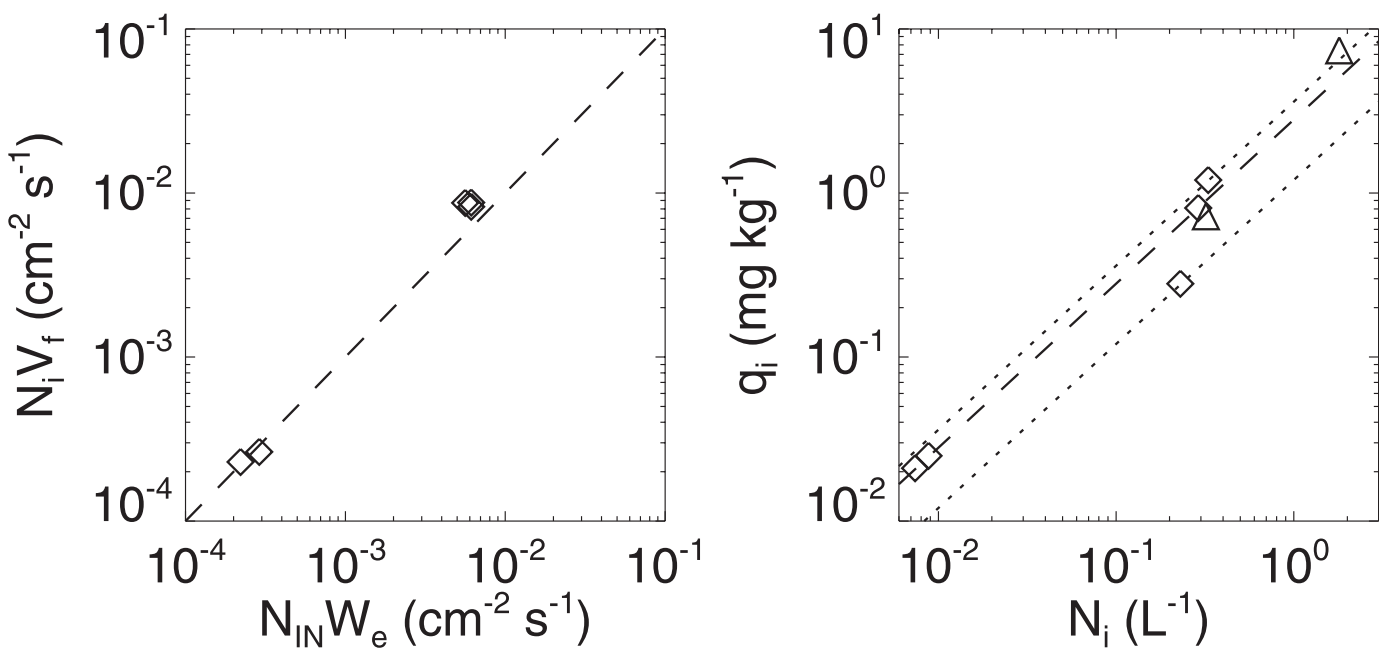

FIG. 12. Simulation results with prognostic IN (diamonds) and diagnostic IN (triangles) averaged over the last $2 \mathrm{~h}$ of simulation time (corresponding to 2200-2400 UTC). (left) Prognostic IN only: supply rate of IN to the boundary layer $N_{\mathrm{IN}} w_{e}$ vs loss rate of ice crystals to the surface $N_{i} v_{f}$, where dashed line indicates 1:1. (right) Domainmean $N_{i}$ vs $q_{i}$ below cloud base, where dashed line indicates linear relation in simulations with prognostic IN and radiating plates, and dotted lines indicate linear relations expected with prognostic IN and aggregates (lower dotted line) or sectored plates (upper dotted line). Values taken from Table 3 for the following simulations: steady-state prognostic IN, baseline, IN $\times 30$, aggregates, plates, modified diagnostic IN, and GCSS submission.

et al. 2011), where DHARMA ice properties were based on radiating plates as in most simulations here. A nearequilibrium LWP was achieved with $1.7 \mathrm{~L}^{-1} \mathrm{IN}$ treated diagnostically in the DHARMA baseline submission to that study (Morrison et al. 2011, their Fig. 4), in contrast to the rapid loss of LWP found in this study (see Fig. 6, solid lines). This is principally because the specified horizontal advective moisture convergence, which generally cannot be adequately constrained by reanalysis fields, was larger in the GCSS SHEBA case (see Fig. A4) and was therefore able to balance a higher rate of desiccation associated with $N_{i}$ of $1.7 \mathrm{~L}^{-1}$. In simulations of mixed-phase Arctic clouds observed during the Beaufort Arctic Storms Experiment, Jiang et al. (2000) demonstrated how an observed quasi-equilibrium LWP can be achieved over a wide range of possible $N_{i}$ when offsetting changes in advective tendencies are made. The very large uncertainty in observations of both $N_{i}$ and advective tendencies therefore introduces a large corresponding uncertainty in modeling case studies.

However, in our baseline DHARMA submission to the GCSS SHEBA intercomparison study, we found that radar reflectivities during 1200-2400 UTC exceeded MMCR measurements by greater than $10 \mathrm{dBZ}$ (Fig. $8 \mathrm{~m}$ ), consistent with the possibility that ice crystal number concentrations were too high (Fig. 7h). That the mean Doppler velocity distribution nonetheless appeared quite similar to measurements (Fig. 8n) suggested that simulated ice properties might be reasonable. Aside we note that LWP fell roughly fourfold over 1200-2400 UTC
(Morrison et al. 2011, their Fig. 4), although radar reflectivity and mean Doppler velocity distributions appear roughly similar during 1200-2400 and 2200-2400 UTC (see Figs. 8m,n). In this study, using the adjusted case specification, which achieves quasi-equilibrium LWP under ice-free conditions, we are able to simultaneously reproduce sustained LWP, ice crystal number size distribution features, radar reflectivities, and mean Doppler velocities. However, this can only be done with prognostic IN, which always produces $N_{i} \ll N_{\text {IN }}$, and it also requires overlying $N_{\text {IN }}$ to be elevated by a factor of about 30 . Then simulated $N_{i}$ reaches about $0.3 \mathrm{~L}^{-1}$, similar to the GCSS SHEBA study sensitivity test with diagnostic $N_{\text {IN }}$ of about $0.2 \mathrm{~L}^{-1}$ in which DHARMA and other models predict increased LWP.

Finally, we find here that a modified diagnostic $N_{\text {IN }}$ fixed at $0.29 \mathrm{~L}^{-1}$ rather than $1.7 \mathrm{~L}^{-1}$ (see Fig. 10) can also reproduce measurements quite well. Crystals smaller than $200 \mu \mathrm{m}$ are enhanced below cloud compared with prognostic IN, but the size distribution of larger ice is minimally affected (Fig. $7 \mathrm{~g}$ ), leading to little change in radar reflectivities and mean Doppler velocities (Figs. 8k,l). Aside we note that had ice instead been treated as aggregates in our baseline submission to the GCSS SHEBA intercomparison study, median reflectivity would have dropped about $5 \mathrm{dBZ}$ (not shown) versus dropping about $10 \mathrm{~dB} Z$ with prognostic IN in this study; the sensitivity to ice habit using diagnostic IN is less than that using prognostic IN because the impact of habit on ice loss rate is flexibly compensated by an unlimited source of new ice crystals. 

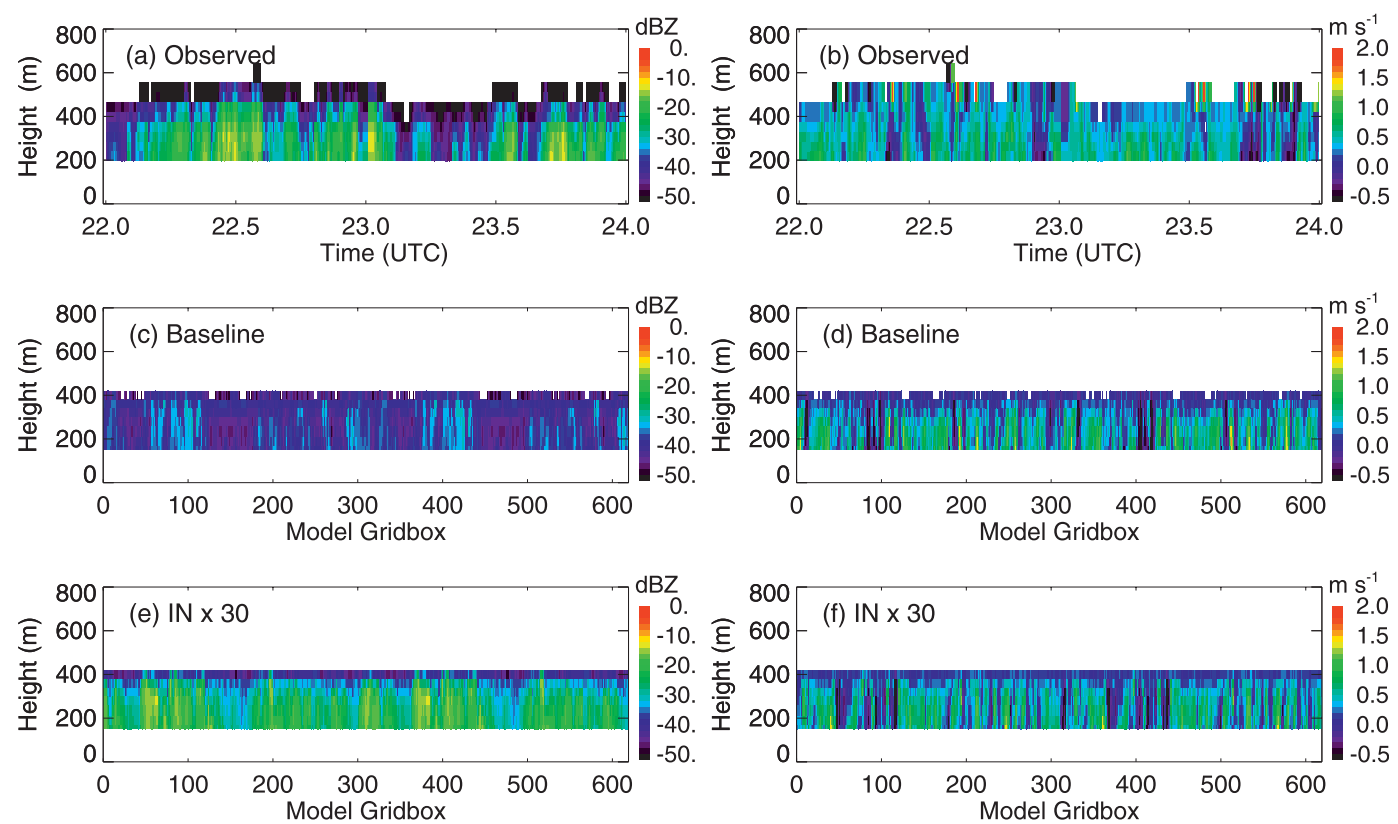

FIG. 13. Observed and simulated (left) radar reflectivity and (right) mean Doppler velocity. Observed 35-GHz reflectivity and Doppler velocity measured by the MMCR during (a),(b) 2200-2400 UTC 7 May 1998. Simulations listed in Table 2: (c), (d) baseline and (e), (f) IN $\times 30$. Simulation results calculated at $3 \mathrm{~h}$ (corresponding to 2300 UTC).

We note that solving Eq. (3) for $N_{\mathrm{IN}}$ required to support $N_{i}$ of $1.7 \mathrm{~L}^{-1}$ using $w_{e} \approx 0.3 \mathrm{~cm} \mathrm{~s}^{-1}$ and $v_{f} \approx$ $30 \mathrm{~cm} \mathrm{~s}^{-1}$ (see GCSS submission in Table 3 ) gives an $N_{\text {IN }}$ of about $200 \mathrm{~L}^{-1}$, which is high compared with typically measured conditions (e.g., DeMott et al. 2010). Overall, based on our model results compared with forwardsimulated radar variables and in situ ice crystal size distributions, we hypothesize that actual $N_{i}$ were sustained closer to 0.17 than $1.7 \mathrm{~L}^{-1}$. However, the discrepancy between $N_{\text {IN }}$ observed and $N_{\text {IN }}$ required to reproduce observed ice properties in our adjusted case study here indicates that substantial problems remain in either the model, the case study formulation, and/or the observational dataset. These results are rather similar to past findings in the 10 October M-PACE case study (e.g., Fridlind et al. 2007; Fan et al. 2009), but contrast with relatively greater success matching simultaneously observed $N_{i}$ and $N_{\text {IN }}$ in the 8 April ISDAC case study (Avramov et al. 2011).

\section{g. Horizontal heterogeneity of ice}

As shown above, when simulations approximately reproduce observed ice crystal size distributions, they also roughly reproduce observed radar reflectivities. However, radar observations indicate a range in reflectivity over 2200-2400 UTC that is notably greater than simulated (e.g., Fig. 8e). Furthermore, periods of low reflectivity were of extended duration (Fig. 13a), as during 2300-2350 UTC, which at about 30 min duration at cloud-level horizontal wind speeds corresponds to a horizontal distance of about $8 \mathrm{~km}$ that is about 10 times the boundary layer depth. Periods of similar duration were characterized by higher radar reflectivities. Observations during 1200-2200 UTC indicate that such variability was commonplace in this cloud deck (cf. Morrison et al. 2011).

Using the visualization method described by van Diedenhoven et al. (2009), Figs. 13c and 13e illustrate how our simulations fail to reproduce observed variability in reflectivity. Increasing domain size to $12.8 \times$ $12.8 \mathrm{~km}^{2}$ produces indistinguishable results (not shown), consistent with a weak feedback of the nonsublimating icephase precipitation on convective dynamics, which contrasts with a strong feedback of evaporating liquid-phase precipitation (cf. Feingold et al. 2010). But we cannot rule out that a much larger domain size or longer-duration case study would produce other results. Such pronounced alternating reflectivity features on horizontal scales many times greater than the boundary layer depth were not present in the 10 October M-PACE or 8 April ISDAC cases, where the observed variability of radar reflectivity was reliably reproduced by various simulations (van Diedenhoven et al. 2009; Avramov et al. 2011). Here periods of lower reflectivity tend to resemble the baseline simulation, whereas periods of higher reflectivity resemble the simulation with enhanced IN concentration. It is uncertain what modifications to the model setup used 
here would be needed to reproduce the observed degree of horizontal variability in cloud ice.

\section{Conclusions and implications}

We adjusted the GCSS SHEBA case study for mixedphase boundary layer clouds observed during 12002400 UTC on 7 May 1998 (Morrison et al. 2011) in order to more closely match conditions during the briefer 2000-2400 UTC time span when airborne ice particle size distribution measurements were obtained. Our principal objective is to determine whether simulations can reproduce all available measurements when using the mean ice nucleus (IN) number concentration $N_{\text {IN }}$ measured above cloud. Since in situ measurements of ice crystal total number concentration $N_{i}$ were unreliable, we compare simulation results with 1) in situ measurements of the size distribution of ice with maximum dimension larger than $200 \mu \mathrm{m}$ and 2) ground-based remote sensing measurements of cloud radar reflectivity and mean Doppler velocity. Results can be briefly summarized as follows.

1) When $N_{\text {IN }}$ is initialized to the observed mean, treating IN prognostically (accounting for consumption when activated) gives dramatically different results than treating IN diagnostically (neglecting consumption by definition), which is not a new finding (e.g., Harrington and Olsson 2001; Rasmussen et al. 2002; Morrison et al. 2005). Consumption depletes rapidly activated IN from a well-mixed boundary layer within minutes. This large difference in model results has important implications for interpreting simulations that treat IN diagnostically (e.g., Jiang et al. 2000). Namely, diagnostic $N_{\text {IN }}$ should be interpreted as incloud $N_{i}$, which may differ substantially from $N_{\text {IN }}$ in cloud-free air that is entrained.

2) When treating IN prognostically, simulated consumption proceeds rapidly in all nucleation modes except contact, which proceeds too slowly to be a significant source of ice crystals if IN are assumed to be $0.5 \mu \mathrm{m}$ in diameter, the mean effective dimension measured by the CFDC during SHEBA (Rogers et al. 2001). It has been argued that contact nucleation could play an important role under SHEBA conditions (Morrison et al. 2005), but available measurements are insufficient to constrain actual contact nucleation rates. Results are insensitive to the whether IN are alternatively activated in the deposition, condensation, or immersion modes. Here we have neglected possible effects of nucleation mode on ice habit (Bailey and Hallett 2002; Bacon et al. 2003), which could conceivably be important since results are sensitive to habit.
3) If rapidly activated IN are the principal source of new ice crystals, as commonly assumed (e.g., Fan et al. 2009), we find that a factor of about 30 greater $N_{\text {IN }}$ than observed is required to reproduce observed ice crystal size distributions and cloud radar reflectivities when accounting for IN consumption. Although radar reflectivities are weighted toward larger particles than ice number size distributions, both exhibit peaks in the 200-1000- $\mu \mathrm{m}$ size range spanned by a single ice mode (cf. Figs. 7 and 9). Thus, measured $N_{\text {IN }}$ appear insufficient to explain observed ice in this case study. It is unknown to what degree the factor of about 30 discrepancy found here can be attributed to observational uncertainties or modeling shortcomings. For instance, the CFDC is not designed to measure IN larger than about $2 \mu \mathrm{m}$ in diameter and may undercount IN active in the contact mode (e.g., Rogers et al. 2001; McFarquhar et al. 2011). In the 10 October M-PACE case, similar results using two independent models led to the speculative consideration of novel ice formation mechanisms unconstrained by CFDC measurements of $N_{\text {IN }}$ (e.g., Fridlind et al. 2007; Fan et al. 2009), but an 8 April ISDAC case study shows less discrepancy, which is on the order of experimental uncertainty (Avramov et al. 2011). Although blowing snow is not generally lifted at the low horizontal wind speeds observed in this case (e.g., Walden et al. 2003), it cannot be ruled out as a conceivable ice crystal source over pack ice.

4) When IN are rapidly consumed, $N_{i}$ is always more than two orders of magnitude smaller than overlying $N_{\text {IN }}$. Under the microphysically simple conditions of this case (apparently negligible ice aggregation, sublimation, and multiplication), in the equilibrium state of a simple mixed-layer model for $N_{i}$ [Eq. (3)], $N_{i} / N_{\text {IN }}$ equals the entrainment rate $w_{e}$ divided by the number-weighted ice fall speed at the surface $v_{f}$. Here $w_{e} / v_{f} \ll 1$ since $w_{e}<1 \mathrm{~cm} \mathrm{~s}^{-1}$ and $v_{f}>$ $10 \mathrm{~cm} \mathrm{~s}^{-1}$. Conditions where $N_{i} / N_{\text {IN }} \ll 1$ contrast with conditions where the IN supply rate is not limited by entrainment (e.g., in a wave cloud; Eidhammer et al. 2010), with implications for interpreting regional measurements. For instance, Prenni et al. (2009) point to observations of $N_{i} \approx N_{\text {IN }}$ in the Arctic as evidence that 1 ) observed $N_{\text {IN }}$ are adequate to explain observed ice and 2) secondary ice sources are not important. But here $N_{i} \approx N_{\text {IN }}$ would be evidence that secondary ice sources must be important (otherwise $N_{i} \ll N_{\text {IN }}$ ). Finally, to the extent that $N_{i} / N_{\mathrm{IN}} \approx w_{e} / v_{f}<1$, entrainment rate limitations on the IN supply rate serve as a buffer on cloud system sensitivity to increasing overlying $N_{\text {IN }}$ in the sense outlined by Stevens and Feingold (2009). Aggregation could decrease sensitivity, whereas 
multiplication (e.g., Yano and Phillips 2011) could increase it. We note that blowing snow, seeding from aloft, or any other ice crystal formation processes not related to entrained IN or existing ice would introduce independent source terms in Eq. (1).

5) Simulations fail to reproduce the observed horizontal heterogeneity of radar reflectivity even when domain size is increased. Pronounced alternating increases and decreases of reflectivity on horizontal scales of about 10 times the boundary layer depth distinguish this case from the 10 October M-PACE and 8 April ISDAC cases with mixed-phase cloud layers (see section $4 \mathrm{~g}$ ). The contributing dynamical and microphysical causes are unknown, and it is uncertain what modifications to the model setup used here would be needed to reproduce the observed heterogeneity.

6) Simulation results are sensitive to assumed ice properties not adequately constrained by measurements, consistent with previous work (e.g., Morrison and Pinto 2006; Avramov and Harrington 2010). The irregular habits that exist in mixed-phase clouds present a challenge to models (e.g., Bailey and Hallett 2002). For this study, the most appropriate observational constraints would have been direct singleparticle field measurements of ice crystal mass, maximum dimension, projected area, aspect ratio, and terminal fall speed, suitable to identify both mean properties and their spread. Such measurements could be made simultaneously at ground level (e.g., Kajikawa 1972), perhaps in part by instruments that could be deployed unattended (e.g., Newman et al. 2009; Barthazy et al. 2004).

Acknowledgments. This research used resources of the National Energy Research Scientific Computing Center, which is supported by the Office of Science of the U.S. Department of Energy under Contract DE-AC02-05CH11231. Fridlind and Ackerman were supported by the DOE Office of Science, Office of Biological and Environmental Research, through Interagency Agreements DE-AI02-06ER64173 and DEAI02-08ER64547, the NASA Radiation Sciences Program, and the NASA Advanced Supercomputing Division. We thank the SHEBA Atmospheric Surface Flux Group, Ed Andreas, Chris Fairall, Peter Guest, and Ola Persson for collecting and processing the tower data. The National Science Foundation supported their research with grants to the U.S. Army Cold Regions Research and Engineering Laboratory, NOAA's Environmental Technology Laboratory, and the Naval Postgraduate School.
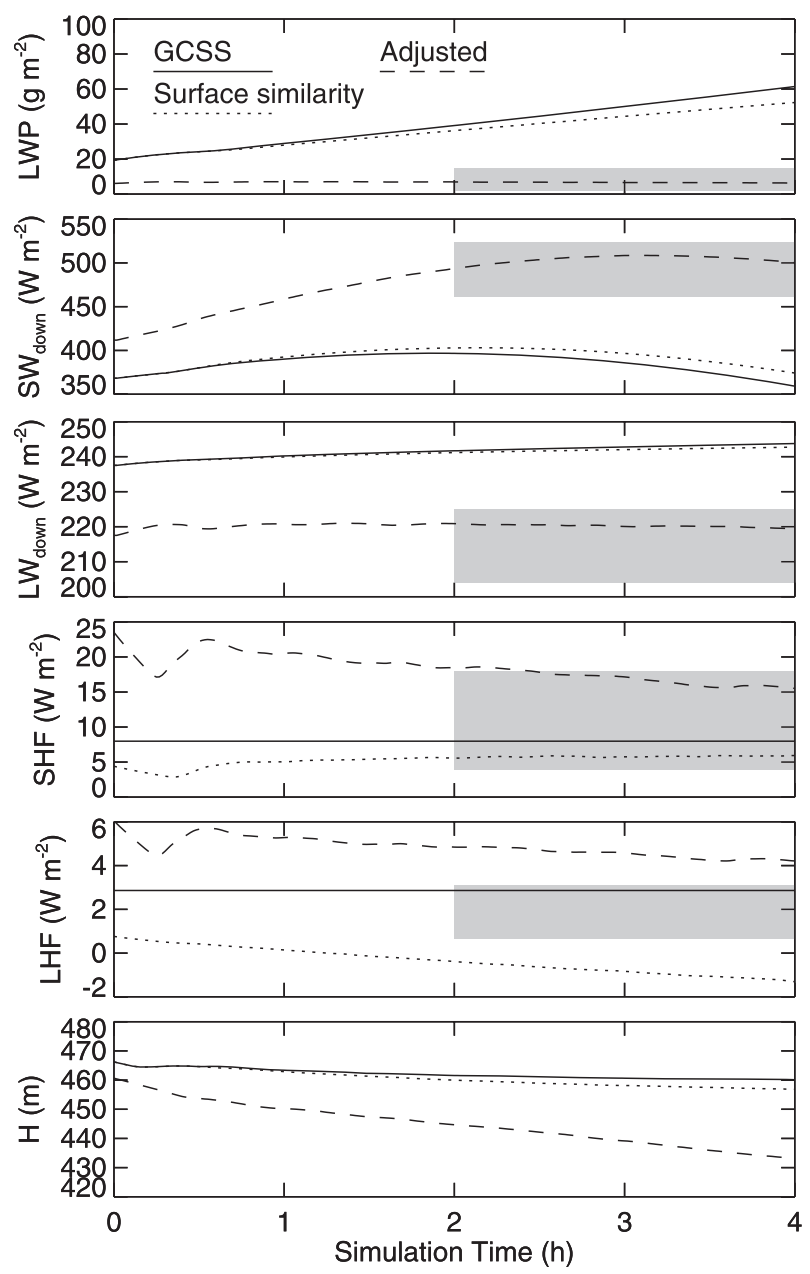

FIG. A1. Observed and simulated domain-mean LWP, surface downwelling shortwave and longwave radiative fluxes $\left(\mathrm{SW}_{\mathrm{down}}\right.$ and $\mathrm{LW}_{\text {down }}$ ), surface sensible and latent heat fluxes (SHF and LHF), and boundary layer depth $H$ (defined by mean elevation where liquid water potential temperature is $258 \mathrm{~K}$; not recorded in observations). Simulations: bulk warm microphysics with the GCSS model intercomparison specification (solid lines), with surface fluxes predicted using similarity theory (dotted lines), and with adjusted initial conditions and large-scale forcings (dashed lines). Observed range (shaded) is during 2200-2400 UTC 7 May 1998 with estimated uncertainty (cf. Persson et al. 2002).

NCEP reanalysis data provided by the NOAA/OAR/ ESRL PSD, Boulder, Colorado, from their website at http://www.esrl.noaa.gov/psd/.

\section{APPENDIX}

\section{Case Study Development}

Here our objective is to make several adjustments to the 1200-2400 UTC 7 May 1998 GCSS SHEBA case study (Morrison et al. 2011) in order to achieve 

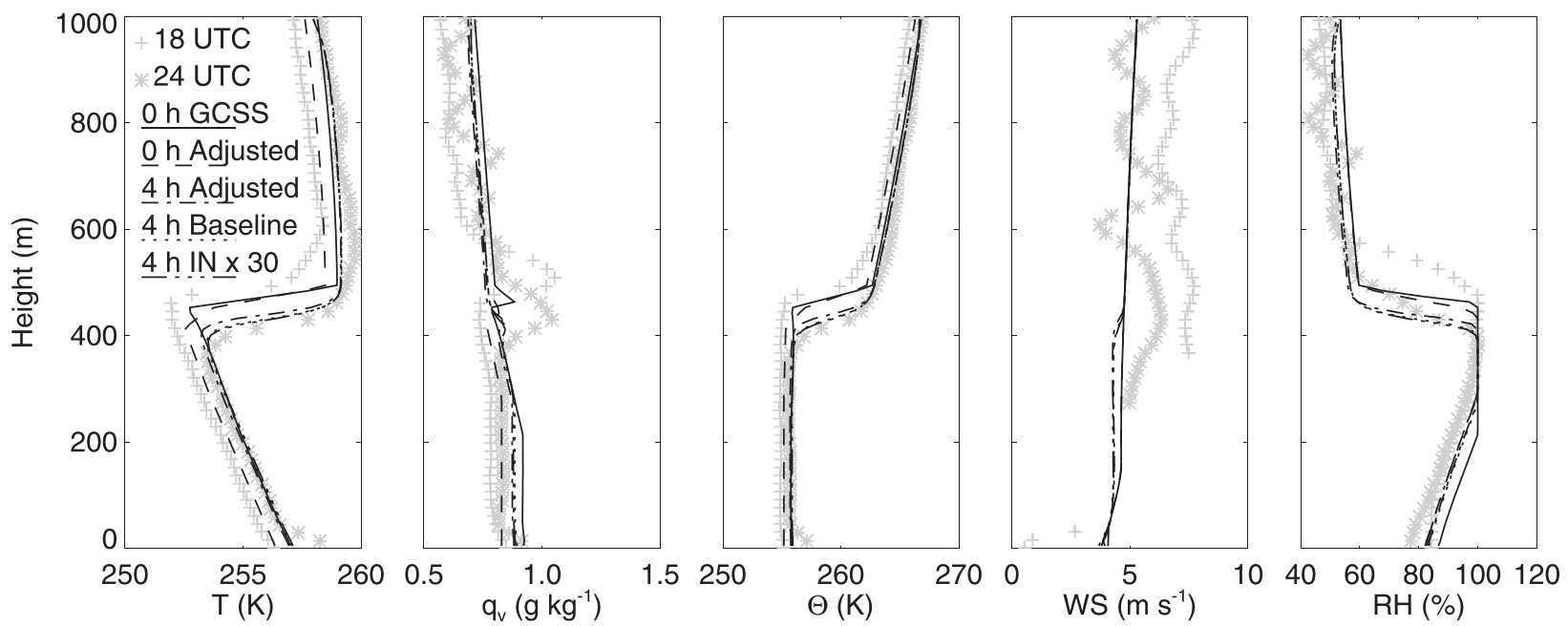

FIG. A2. Observed and simulated profiles of temperature $T$, water vapor mixing ratio $q_{v}$, potential temperature $\theta$, horizontal wind speed (WS), and relative humidity (RH). Observations at 1800 and 2400 UTC (plus and asterisk symbols, respectively). Simulations using bulk warm microphysics with the GCSS model intercomparison specification (solid lines at $0 \mathrm{~h}$, initial condition) and with adjusted initial conditions and large-scale forcings (dashed and dash-dotted lines at 0 and $4 \mathrm{~h}$ ), and in baseline simulations using mixed-phase bin microphysics (dotted line at $4 \mathrm{~h}$, initial condition same as adjusted case) and with $\mathrm{IN} \times 30$ (dash-triple-dotted lines at $4 \mathrm{~h}$, initial condition same as adjusted case). Simulation times of 0 and $4 \mathrm{~h}$ correspond to 2000 and 2400 UTC.

reasonably close simultaneous agreement with the following observed conditions specifically during 2200 2400 UTC: liquid water path (LWP), surface upwelling and downwelling radiative fluxes, surface skin temperature, $10-\mathrm{m}$ tower measurements of temperature and water vapor, surface turbulent heat fluxes, and observed profiles of temperature, water vapor, potential temperature, and wind speed. The GCSS model intercomparison specification for 12-h simulations was based on a combination of observations, reanalysis fields (European Centre for Medium-Range Weather Forecasts), and model results. Here we shorten the simulation time to $4 \mathrm{~h}$, allowing $2 \mathrm{~h}$ for model spinup before comparison of simulated conditions during hours 2-4 with observations from 2200 to 2400 UTC.

The effects of ice can be neglected during case study development because desiccation remains relatively weak when ice crystal number size distribution features match the available observations (shown in section 4). We therefore save computational time by using an efficient bulk warm microphysics scheme that consists of condensational adjustment with slow sedimentation of cloud droplets following Ackerman et al. (2009). Droplet number concentration $N_{d}$ is fixed at $215 \mathrm{~cm}^{-3}$, consistent with observations. At the very low ratio of observed LWP to $N_{d}$ here $\left(\sim 0.02 \mathrm{~g} \mathrm{~m}^{-2} \mathrm{~cm}^{3}\right)$, gravitational collection can be neglected (cf. Comstock et al. 2004, their Fig. 10). A lognormal droplet size distribution with a geometric standard deviation of 1.3 is assumed for radiative transfer and sedimentation.
We start with the initial and boundary conditions and large-scale forcings from the GCSS SHEBA case. LWP is initially $20 \mathrm{~g} \mathrm{~m}^{-2}$, consistent with an average of observations over 1200-2400 UTC but greater than observed during 2200-2400 UTC (Fig. A1, solid lines). At 4 h, simulated LWP is roughly 5 times greater than observed, resulting in underprediction and overprediction of surface downwelling shortwave and longwave radiative fluxes, respectively. Predicted LWP is not sensitive to replacing the fixed surface latent and sensible heat fluxes specified in the model intercomparison with interactive fluxes predicted at grid scale using similarity theory (Fig. A1, dotted lines).

We first make several adjustments to reduce initial LWP and simultaneously improve consistency with 22002400 UTC observations. The initial temperature $T$ profile is made uniformly colder by $0.5 \mathrm{~K}$, the water vapor mixing ratio in the boundary layer limited to $q_{v} \leq 0.829 \mathrm{~g} \mathrm{~kg}^{-1}$, and all profiles shifted downward by $10 \mathrm{~m}$. These changes bring initial conditions closer to the 1800 UTC sounding (Fig. A2). Aside we note that reported $q_{v}$ and $T$ profiles correspond to an LWP that is far greater than retrieved from observations, presumably owing to measurement bias. We accept $T$ as the more reliably measured parameter and use reported LWP to constrain initial $q_{v}$. Surface skin temperature is increased by $1 \mathrm{~K}$ (Fig. A3).

With adjustments to initial and boundary conditions in place, we turn next to large-scale forcing terms. To emulate the observed evolution of the $T$ profile, we increase the potential temperature horizontal advective 

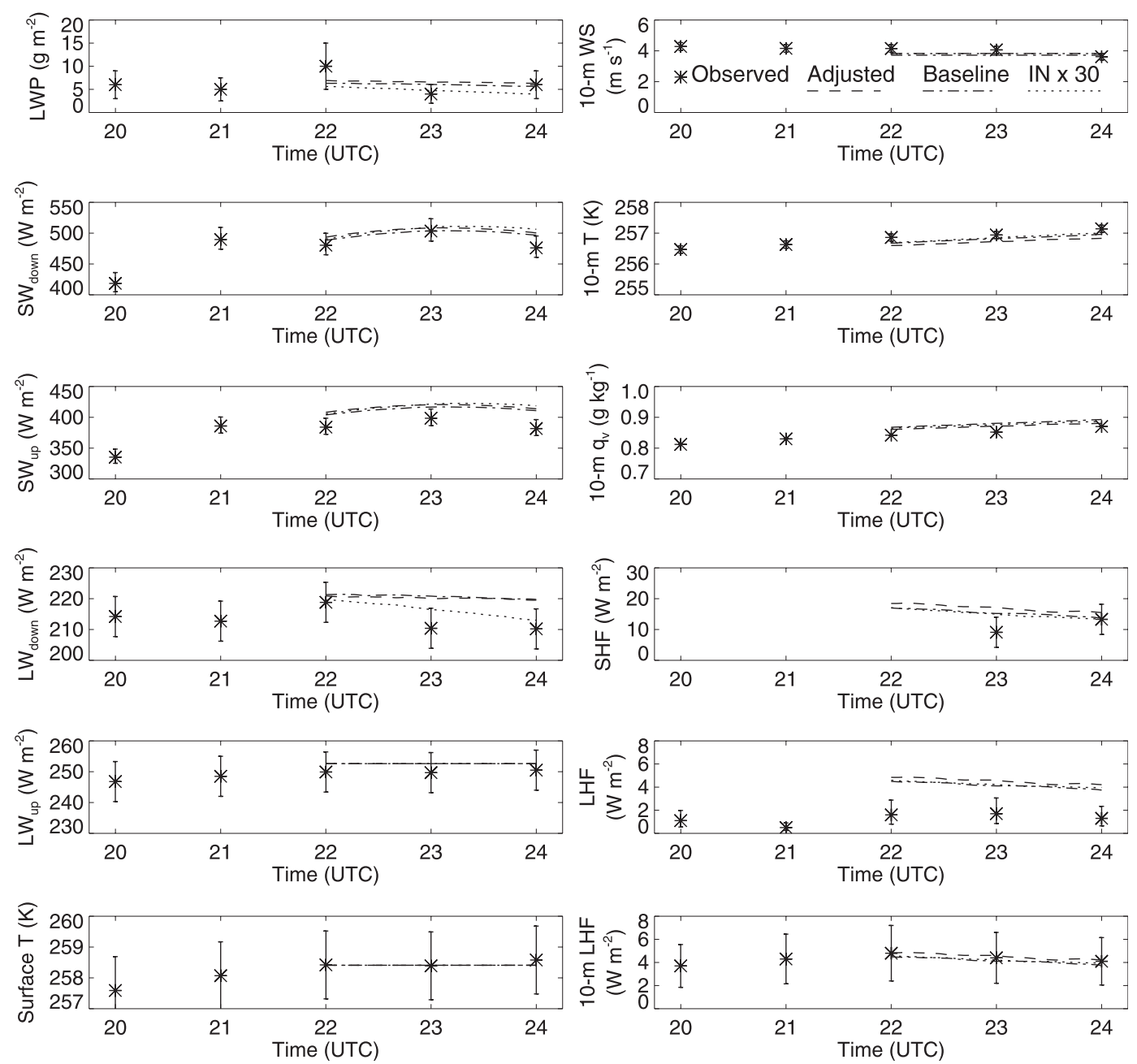

FIG. A3. Observed and simulated time series of LWP, upwelling and downwelling shortwave and longwave radiative fluxes $\left(\mathrm{SW}_{\mathrm{down}}, \mathrm{SW}_{\mathrm{up}}, \mathrm{LW}_{\mathrm{down}}, \mathrm{LW}_{\mathrm{up}}\right.$ ), surface skin temperature, 10-m wind speed (WS), 10-m air temperature and water vapor mixing ratio $q_{v}$, surface SHF and LHF, and 10-m LHF. Hourly observations calculated from tower and surface measurements [asterisks with uncertainty range (cf. Persson et al. 2002), see section 2]. Simulations use bulk microphysics with adjusted initial conditions and large-scale forcings (dashed lines), and mixed-phase bin microphysics in the baseline case (dash-dotted lines) and with IN $\times 30$ (dotted lines).

tendency to a vertically uniform value of $2 \mathrm{~K} \mathrm{day}^{-1}$. This is larger at most elevations than in the 12 -h GCSS specification and larger than indicated from analysis of NCEP fields (Fig. A4), but we consider agreement with 1800 and 2400 UTC soundings a better constraint. Last, we adjust the $q_{v}$ horizontal advective tendency to a vertically uniform value of $0.02 \mathrm{~g} \mathrm{~kg}^{-1} \mathrm{day}^{-1}$ in order to achieve LWP within the observed range and at quasi-equilibrium, which we define for a parameter by requiring its $e$-folding time (computed from a 1-h running mean of domain averages reported every minute) to continuously exceed $10 \mathrm{~h}$ during simulation hours 3 and 4. The adjusted moisture horizontal advective tendency is smaller than most NCEP values, but is constrained relative to other forcings if LWP is to maintain quasi-equilibrium (see also section $4 \mathrm{f}$ ).
A simulation with all foregoing changes achieves relatively close agreement with LWP, upwelling and downwelling surface radiative fluxes, surface skin $T, 10-\mathrm{m}$ tower measurements of $T$ and $q_{v}$, surface sensible heat flux, and observed profiles of $T, q_{v}$, potential temperature, wind speed, and relative humidity (see Figs. A2 and A3). A notable exception is disagreement with measured surface latent heat flux, although agreement with bulk calculations at $10 \mathrm{~m}$ is very good; the cause for persistent disagreement between bulk calculations and measured latent heat fluxes at the surface is unknown (Persson et al. 2002). Finally, a net effect of all adjustments is a reduction in cloud-top entrainment such that boundary layer depth falls by about $30 \mathrm{~m}$ over $4 \mathrm{~h}$ (see Fig. A1), which improves consistency with 

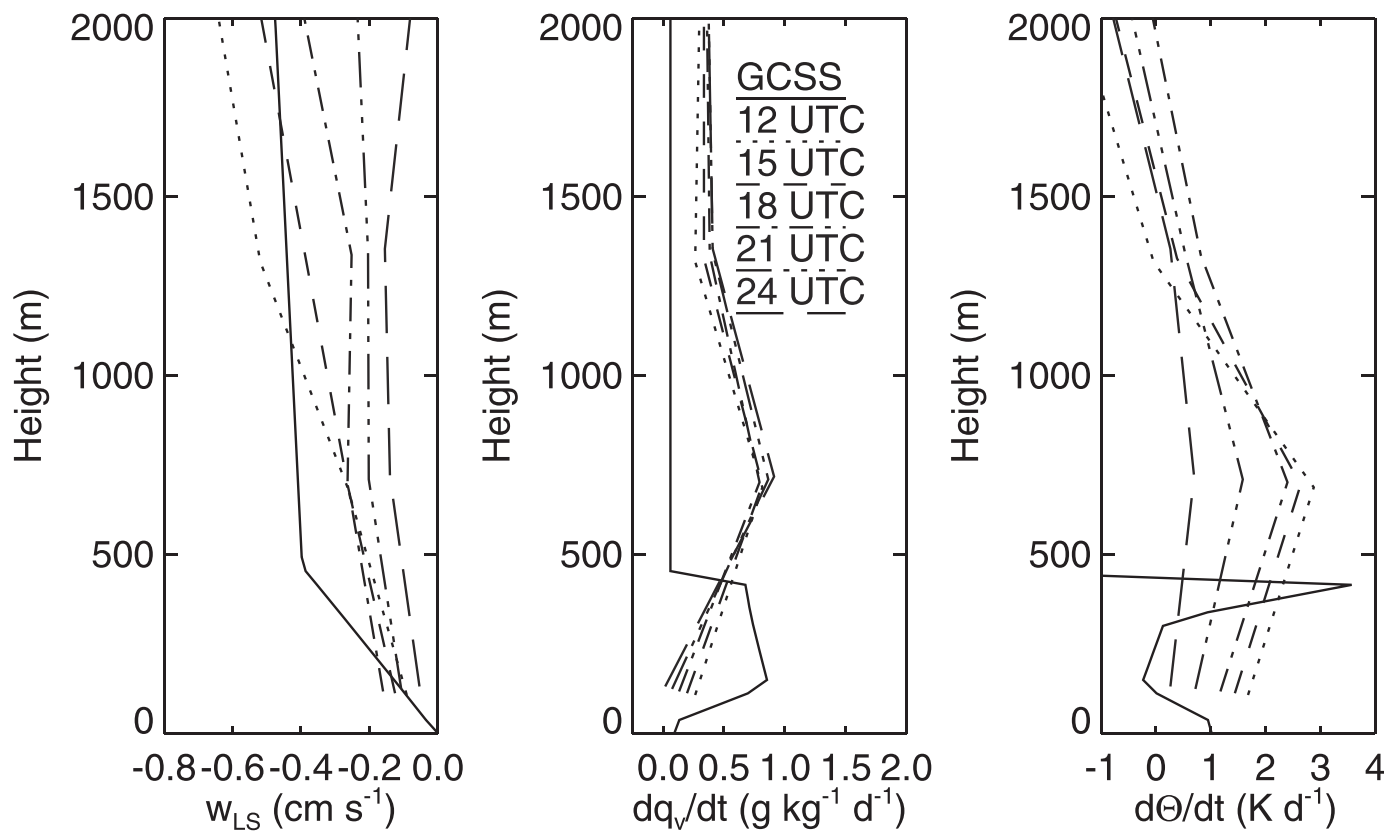

FIG. A4. Derived profiles of large-scale vertical wind $w_{\text {LS }}$ and advective tendencies of water vapor and potential temperature specified in the GCSS intercomparison (solid lines) and derived from NCEP reanalysis fields for 7 May 1998 (other line types, see legend).

MMCR observations and soundings somewhat (cf. Fig. A2).

\section{REFERENCES}

Ackerman, A. S., O. B. Toon, and P. V. Hobbs, 1995: A model for particle microphysics, turbulent mixing, and radiativetransfer in the stratocumulus-topped marine boundarylayer and comparisons with measurements. J. Atmos. Sci., 52, 1204-1236.

- and Coauthors, 2009: Large-eddy simulations of a drizzling, stratocumulus-topped marine boundary layer. Mon. Wea. Rev., 137, 1083-1110.

Avramov, A., and J. Y. Harrington, 2010: Influence of parameterized ice habit on simulated mixed phase Arctic clouds. J. Geophys. Res., 115, D03205, doi:10.1029/2009JD012108.

— , and Coauthors, 2011: Toward ice formation closure in Arctic mixed-phase boundary layer clouds during ISDAC. J. Geophys. Res., 116, D00T08, doi:10.1029/2011JD015910.

Bacon, N., M. Baker, and B. Swanson, 2003: Initial stages in the morphological evolution of vapour-grown ice crystals: A laboratory investigation. Quart. J. Roy. Meteor. Soc., 129, 1903-1927.

Bailey, M., and J. Hallett, 2002: Nucleation effects on the habit of vapour grown ice crystals from -18 to $-42^{\circ} \mathrm{C}$. Quart. J. Roy. Meteor. Soc., 128, 1461-1483.

- , and - 2004: Growth rates and habits of ice crystals between $-20^{\circ}$ and $-70^{\circ}$ C. J. Atmos. Sci., 61, 514-544.

Baker, B., and R. P. Lawson, 2006: Improvement in determination of ice water content from two-dimensional particle imagery. Part I: Image-to-mass relationships. J. Appl. Meteor. Climatol., 45, 1282-1290.

Barthazy, E., S. Göke, R. Schefold, and D. Högl, 2004: An optical array instrument for shape and fall velocity measurements of hydrometeors. J. Atmos. Oceanic Technol., 21, 14001416.

Beard, K. V., and H. T. Ochs, 1984: Collection and coalescence efficiencies for accretion. J. Geophys. Res., 89 (D5), 7165-7169.

Beesley, J., C. Bretherton, C. Jakob, E. Andreas, J. Intrieri, and T. Uttal, 2000: A comparison of cloud and boundary layer variables in the ECMWF forecast model with observations at Surface Heat Budget of the Arctic Ocean (SHEBA) ice camp. J. Geophys. Res., 105 (D10), 12 337-12 349.

Böhm, H., 1989: A general equation for the terminal fall speed of solid hydrometeors. J. Atmos. Sci., 46, 2419-2417.

Böhm, J. P., 1992a: A general hydrodynamic theory for mixedphase microphysics. Part I: Drag and fall speed of hydrometeors. Atmos. Res., 27 (4), 253-274.

_ 1992b: A general hydrodynamic theory for mixed-phase microphysics. Part II: Collision kernels for coalescence. Atmos. Res., 27 (4), 275-290.

— 1992c: A general hydrodynamic theory for mixed-phase microphysics. Part III: Riming and aggregation. Atmos. Res., 28 (2), 103-123.

_ 1994: Theoretical collision efficiencies for riming and aerosol impaction. Atmos. Res., 32 (1-4), 171-187.

_ 1999: Revision and clarification of 'A general hydrodynamic theory for mixed-phase microphysics'. Atmos. Res., 52 (3), 167-176.

, 2004: Reply to comment on "Revision and clarification of 'A general hydrodynamic theory for mixed-phase microphysics' [Bohm J. P., 1999, Atmos. Res. 52, 167-176]'”. Atmos. Res., 69 (3-4), 289-293.

Brunke, M. A., M. Zhou, X. Zeng, and E. L Andreas, 2006: An intercomparison of bulk aerodynamic algorithms used over sea ice with data from the Surface Heat Budget for the Arctic Ocean (SHEBA) experiment. J. Geophys. Res., 111, C09001, doi:10.1029/2005JC002907. 
Businger, J. A., J. C. Wyngaard, Y. Izumi, and E. F. Bradley, 1971: Flux-profile relationships in the atmospheric surface layer. J. Atmos. Sci., 28, 181-189.

Clark, T. L., 1974: A study in cloud phase parameterization using the gamma distribution. J. Atmos. Sci., 31, 142-155.

Clough, S. A., F. X. Kneizys, and R. W. Davies, 1989: Line shape and the water vapor continuum. Atmos. Res., 23 (3-4), 229-241.

Comstock, K., R. Wood, S. Yuter, and C. Bretherton, 2004: Reflectivity and rain rate in and below drizzling stratocumulus. Quart. J. Roy. Meteor. Soc., 130, 2891-2918.

Curry, J. A., and Coauthors, 2000: FIRE Arctic Clouds Experiment. Bull. Amer. Meteor. Soc., 81, 5-29.

de Boer, G., T. Hashino, and G. J. Tripoli, 2009: Ice nucleation through immersion freezing in mixed-phase stratiform clouds: Theory and numerical simulations. Atmos. Res., 96, 315-324.

DeMott, P. J., and Coauthors, 2010: Predicting global atmospheric ice nuclei distributions and their impacts on climate. Proc. Natl. Acad. Sci. USA, 107, 11 217-11 222.

Dong, X., G. G. Mace, P. Minnis, and D. F. Young, 2001: Arctic stratus cloud properties and their effect on the surface radiation budget: Selected cases from FIRE ACE. J. Geophys. Res., 106 (D14), 15 297-15 312.

Eidhammer, T., and Coauthors, 2010: Ice initiation by aerosol particles: Measured and predicted ice nuclei concentrations versus measured ice crystal concentrations in an orographic wave cloud. J. Atmos. Sci., 67, 2417-2436.

Faloona, I., and Coauthors, 2005: Observations of entrainment in eastern Pacific marine stratocumulus using three conserved scalars. J. Atmos. Sci., 62, 3268-3285.

Fan, J., M. Ovtchinnikov, J. M. Comstock, S. A. Mcfarlane, and A. Khain, 2009: Ice formation in Arctic mixed-phase clouds: Insights from a 3-D cloud-resolving model with size-resolved aerosol and cloud microphysics. J. Geophys. Res., 114, D04205, doi:10.1029/2008JD010782.

Feingold, G., I. Koren, H. Wang, H. Xue, and W. A. Brewer, 2010: Precipitation-generated oscillations in open cellular cloud fields. Nature, 466, 849-852.

Field, P., A. Heymsfield, and A. Bansemer, 2006: Shattering and particle interarrival times measured by optical array probes in ice clouds. J. Atmos. Oceanic Technol., 23, 1357-1371.

Fridlind, A. M., A. S. Ackerman, G. McFarquhar, G. Zhang, M. R. Poellot, P. J. DeMott, A. J. Prenni, and A. J. Heymsfield, 2007: Ice properties of single-layer stratocumulus during the MixedPhase Arctic Cloud Experiment: 2. Model results. J. Geophys. Res., 112, D24202, doi:10.1029/2007JD008646.

Girard, E., and J. Blanchet, 2001: Simulation of Arctic diamond dust, ice fog, and thin stratus using an explicit aerosol-cloudradiation model. J. Atmos. Sci., 58, 1199-1221.

_ , and J. Curry, 2001: Simulation of Arctic low-level clouds observed during the FIRE Arctic Clouds Experiment using a new bulk microphysics scheme. J. Geophys. Res., 106D, $15139-15154$

Gorodetskaya, I. V., L. Tremblay, B. Liepert, M. A. Cane, and R. I. Cullather, 2008: The influence of cloud and surface properties on the Arctic Ocean shortwave radiation budget in coupled models. J. Climate, 21, 866-882.

Harrington, J. Y., and P. Q. Olsson, 2001: On the potential influence of ice nuclei on surface-forced marine stratocumulus cloud dynamics. J. Geophys. Res., 106, 27 473-27 484.

Hashino, T., and G. J. Tripoli, 2007: The Spectral Ice Habit Prediction System (SHIPS). Part I: Model description and simulation of the vapor deposition process. J. Atmos. Sci., 64, 2210-2237.
Haynes, J. M., R. T. Marchand, Z. Luo, A. Bodas-Salcedo, and G. L. Stephens, 2007: A multipurpose radar simulation package: QuickBeam. Bull. Amer. Meteor. Soc., 88, 1723-1727.

Heymsfield, A. J., and S. C. Mossop, 1984: Temperature dependence of secondary ice crystal production during soft hail growth by riming. Quart. J. Roy. Meteor. Soc., 110, 765-770.

— , and C. Westbrook, 2010: Advances in the estimation of ice particle fall speeds using laboratory and field measurements. J. Atmos. Sci., 67, 2469-2482.

Holland, M. M., M. C. Serreze, and J. Stroeve, 2008: The sea ice mass budget of the Arctic and its future change as simulated by coupled climate models. Climate Dyn., 34, 185-200, doi:10.1007/ s00382-008-0493-4.

Inoue, J., J. Liu, J. Pinto, and J. Curry, 2006: Intercomparison of Arctic regional climate models: Modeling clouds and radiation for SHEBA in May 1998. J. Climate, 19, 4167-4178.

Intrieri, J., M. Shupe, T. Uttal, and B. McCarty, 2002: An annual cycle of Arctic cloud characteristics observed by radar and lidar at SHEBA. J. Geophys. Res., 107, 8030, doi:10.1029/ 2000JC000423.

Jensen, E. J., and Coauthors, 1998: Ice nucleation processes in upper tropospheric wave-clouds observed during SUCCESS. Geophys. Res. Lett., 25, 1363-1366.

Jiang, H., W. R. Cotton, J. Pinto, J. Curry, and M. J. Weissbluth, 2000: Cloud resolving simulations of mixed-phase Arctic stratus observed during BASE: Sensitivity to concentration of ice crystals and large-scale heat and moisture advection. J. Atmos. Sci., 57, 2105-2117.

Kajikawa, M., 1972: Measurement of falling velocity of individual snow crystals. J. Meteor. Soc. Japan, 50, 577-583.

Kalnay, E., and Coauthors, 1996: The NCEP/NCAR 40-Year Reanalysis Project. Bull. Amer. Meteor. Soc., 77, 437-471.

Kirkpatrick, M. P., A. S. Ackerman, D. E. Stevens, and N. N. Mansour, 2006: On the application of the dynamic Smagorinsky model to large-eddy simulations of the cloud-topped atmospheric boundary layer. J. Atmos. Sci., 63, 526-546.

Klein, S. A., and Coauthors, 2009: Intercomparison of model simulations of mixed-phase clouds observed during the ARM Mixed-Phase Arctic Cloud Experiment. I: Single-layer cloud. Quart. J. Roy. Meteor. Soc., 135, 979-1002.

Knopf, D. A., and T. Koop, 2006: Heterogeneous nucleation of ice on surrogates of mineral dust. J. Geophys. Res., 111, D12201, doi:10.1029/2005JD006894.

Korolev, A., and G. Isaac, 2003: Roundness and aspect ratio of particles in ice clouds. J. Atmos. Sci., 60, 1795-1808.

, and - 2005: Shattering during sampling by OAPs and HVPS. Part I: Snow particles. J. Atmos. Oceanic Technol., 22, 528-542.

, —, and J. Hallett, 1999: Ice particle habits in Arctic clouds. Geophys. Res. Lett., 26, 1299-1302.

_ , E. F. Emery, J. W. Strapp, S. G. Cober, G. A. Isaac, M. Wasey, and D. Marcotte, 2011: Small ice particles in tropospheric clouds: Fact or artifact? Airborne Icing Instrumentation Evaluation Experiment. Bull. Amer. Meteor. Soc., 92, 967-973.

Lawson, R. P., and P. Zuidema, 2009: Aircraft microphysical and surface-based radar observations of summertime Arctic clouds. J. Atmos. Sci., 66, 3505-3529.

, B. Baker, C. Schmitt, and T. Jensen, 2001: An overview of microphysical properties of arctic clouds observed in May and July 1998 during FIRE ACE. J. Geophys. Res., 106 (D14), 14 989-15014.

Liljegren, J. C., 2000: Observations of integrated water vapour and cloud liquid water at the SHEBA ice station. Microwave 
Radiometry and Remote Sensing of the Earth's Surface and Atmosphere. P. Pampaloni and S. Paloscia, Eds., VSP Press, 155-163.

Lilly, D. K., 1968: Models of cloud-topped mixed layers under a strong inversion. Quart. J. Roy. Meteor. Soc., 94, 292-309.

Locatelli, J. D., and P. V. Hobbs, 1974: Fall speeds and masses of solid precipitation particles. J. Geophys. Res., 79, 2185-2197.

Lohmann, U., J. Humble, W. Leaitch, G. Isaac, and I. Gultepe, 2001: Simulations of ice clouds during FIRE ACE using the CCCMA single-column model. J. Geophys. Res., 106 (D14), 15 123-15 138.

Lynn, B. H., A. P. Khain, J. Dudhia, D. Rosenfeld, A. Pokrovsky, and A. Seifert, 2005: Spectral (bin) microphysics coupled with a mesoscale model (MM5). Part I: Simulation of a CaPE rain event with a squall line. Mon. Wea. Rev., 133, 59-71.

Magono, C., and C. W. Lee, 1966: Meteorological classification of natural snow crystals. J. Fac. Sci. Hokkaido Univ. Japan Ser. VII, 2 (4), 321-335.

McFarlane, S. A., K. F. Evans, and A. S. Ackerman, 2002: A Bayesian algorithm for the retrieval of liquid water cloud properties from microwave radiometer and millimeter radar data. J. Geophys. Res., 107, 4317, doi:10.1029/2001JD001011.

McFarquhar, G. M., G. Zhang, M. R. Poellot, G. L. Kok, R. McCoy, T. Tooman, A. Fridlind, and A. J. Heymsfield, 2007: Ice properties of single-layer stratocumulus during the Mixed-Phase Arctic Cloud Experiment (MPACE): Part I. Observations. J. Geophys. Res., 112, D24201, doi:10.1029/ 2007JD008633.

—, and Coauthors, 2011: Indirect and Semi-Direct Aerosol Campaign: The impact of Arctic aerosols on clouds. Bull. Amer. Meteor. Soc., 92, 183-201.

Mitchell, D., 1988: Evolution of snow-size spectra in cyclonic storms: Part I: Snow growth by vapor deposition and aggregation. J. Atmos. Sci., 45, 3431-3452.

, 1996: Use of mass- and area-dimensional power laws for determining precipitation particle terminal velocities. J. Atmos. Sci., 53, 1710-1723.

_- R. Zhang, and R. L. Pitter, 1990: Mass-dimensional relationships for ice particles and the influence of riming on snowfall rates. J. Appl. Meteor., 29, 153-163.

Morrison, H., and W. W. Grabowski, 2008: A novel approach for representing ice microphysics in models: Description and tests using a kinematic framework. J. Atmos. Sci., 65, 15281548.

, and J. O. Pinto, 2005: Mesoscale modeling of springtime Arctic mixed-phase stratiform clouds using a new two-moment bulk microphysics scheme. J. Atmos. Sci., 62, 3683-3704.

- and _ 2006: Intercomparison of bulk cloud microphysics schemes in mesoscale simulations of springtime Arctic mixedphase stratiform clouds. Mon. Wea. Rev., 134, 1880-1900.

— M. Shupe, J. Pinto, and J. Curry, 2005: Possible roles of ice nucleation mode and ice nuclei depletion in the extended lifetime of arctic mixed-phase clouds. Geophys. Res. Lett., 32, L18801, doi:10.1029/2005GL023614.

— J. O. Pinto, J. A. Curry, and G. M. McFarquhar, 2008: Sensitivity of modeled arctic mixed-phase stratocumulus to cloud condensation and ice nuclei over regionally varying surface conditions. J. Geophys. Res., 113, D05203, doi:10.1029/ 2007JD008729.

, and Coauthors, 2011: Intercomparison of cloud model simulations of Arctic mixed-phase boundary layer clouds observed during SHEBA/FIRE-ACE. J. Adv. Model. Earth Syst., 3, M05001, doi:10.1029/2011MS000066.
Newman, A. J., P. A. Kucera, and L. F. Bliven, 2009: Presenting the Snowflake Video Imager (SVI). J. Atmos. Oceanic Technol., 26, 167-179.

Persson, P., C. Fairall, E. Andreas, P. Guest, and D. Perovich, 2002: Measurements near the atmospheric surface flux group tower at SHEBA: Near-surface conditions and surface energy budget. J. Geophys. Res., 107, 8045, doi:10.1029/2000JC000705.

Pinto, J., 1998: Autumnal mixed-phase cloudy boundary layers in the Arctic. J. Atmos. Sci., 55, 2016-2038.

Prenni, A. J., and Coauthors, 2007: Can ice-nucleating aerosols affect Arctic seasonal climate? Bull. Amer. Meteor. Soc., 88, $541-550$

, P. J. Demott, D. C. Rogers, S. M. Kreidenweis, G. M McFarquhar, G. Zhang, and M. R. Poellot, 2009: Ice nuclei characteristics from M-PACE and their relation to ice formation in clouds. Tellus, 61B, 436-448.

Pruppacher, H. R., and J. D. Klett, 1997: Microphysics of Clouds and Precipitation. 2nd ed. Kluwer Academic Publishers, $954 \mathrm{pp}$.

Randall, D., and Coauthors, 1998: Status of and outlook for largescale modeling of atmosphere-ice-ocean interactions in the Arctic. Bull. Amer. Meteor. Soc., 79, 197-219.

Rasmussen, R. M., I. Geresdi, G. Thompson, K. Manning, and E. Karplus, 2002: Freezing drizzle formation in stably stratified layer clouds: The role of radiative cooling of cloud droplets, cloud condensation nuclei, and ice initiation. J. Atmos. Sci., 59, 837-860.

Roberts, P., and J. Hallett, 1968: A laboratory study of the ice nucleating properties of some mineral particulates. Quart. J. Roy. Meteor. Soc., 94, 25-34.

Rogers, D., P. DeMott, and S. Kreidenweis, 2001: Airborne measurements of tropospheric ice-nucleating aerosol particles in the Arctic spring. J. Geophys. Res., 106 (D14), $15053-15063$

Sandvik, A., M. Biryulina, N. Kvamstø, J. J. Stamnes, and K. Stamnes, 2007: Observed and simulated microphysical composition of arctic clouds: Data properties and model validation. J. Geophys. Res., 112, D05205, doi:10.1029/2006JD007351.

Shupe, M., T. Uttal, S. Matrosov, and A. Frisch, 2001: Cloud water contents and hydrometeor sizes during the FIRE Arctic Clouds Experiment. J. Geophys. Res., 106 (D14), 15015 15028.

_ - S. Matrosov, and T. Uttal, 2006: Arctic mixed-phase cloud properties derived from surface-based sensors at SHEBA. J. Atmos. Sci., 63, 697-711.

Solomon, A., H. Morrison, O. Persson, M. D. Shupe, and J.-W. Bao, 2009: Investigation of microphysical parameterizations of snow and ice in Arctic clouds during M-PACE through model-observation comparisons. Mon. Wea. Rev., 137, 31103128.

Solomon, S., D. Qin, M. Manning, M. Marquis, K. Averyt, M. M. B. Tignor, H. L. Miller Jr., and Z. Chen, Eds., 2007: Climate Change 2007: The Physical Science Basis. Cambridge University Press, 996 pp.

Sorteberg, A., V. Kattsov, J. Walsh, and T. Pavlova, 2007: The Arctic surface energy budget as simulated with the IPCC AR4 AOGCMs. Climate Dyn., 29, 131-156.

Stevens, B., and G. Feingold, 2009: Untangling aerosol effects on clouds and precipitation in a buffered system. Nature, 461, 607-613.

Stevens, D. E., A. S. Ackerman, and C. S. Bretherton, 2002: Effects of domain size and numerical resolution on the simulation of shallow cumulus convection. J. Atmos. Sci., 59, 3285-3301. 
Toon, O. B., and T. P. Ackerman, 1981: Algorithms for the calculation of scattering by stratified spheres. Appl. Opt., 20, $3657-3660$.

, C. P. McKay, T. P. Ackerman, and K. Santhanam, 1989: Rapid calculation of radiative heating rates and photodissociation rates in inhomogeneous multiple scattering atmospheres. J. Geophys. Res., 94 (D13), 16 287-16 281.

van Diedenhoven, B., A. M. Fridlind, A. S. Ackerman, E. W. Eloranta, and G. M. Mcfarquhar, 2009: An evaluation of ice formation in large-eddy simulations of supercooled Arctic stratocumulus using ground-based lidar and cloud radar. J. Geophys. Res., 114 (D10), D10203, doi:10.1029/2008JD011198.

Vardiman, L., 1978: The generation of secondary ice particles in clouds by crystal-crystal collision. J. Atmos. Sci., 35, 2168-2180.

Verlinde, J., and Coauthors, 2007: The Mixed-Phase Arctic Cloud Experiment (M-PACE). Bull. Amer. Meteor. Soc., 88, 205-221.

Walden, V. P., S. G. Warren, and E. Tuttle, 2003: Atmospheric ice crystals over the Antarctic Plateau in winter. J. Appl. Meteor., 42, 1391-1405.

Wang, C., and J. Chang, 1993: A three-dimensional numerical model of cloud dynamics, microphysics, and chemistry. 1. Concepts and formulation. J. Geophys. Res., 98 (D8), 14 827-14 844.
Westbrook, C. D., R. J. Hogan, and A. J. Illingworth, 2008: The capacitance of pristine ice crystals and aggregate snowflakes. J. Atmos. Sci., 65, 206-219.

Wyant, M. C., C. S. Bretherton, H. A. Rand, and D. E. Stevens, 1997: Numerical simulations and a conceptual model of the stratocumulus to trade cumulus transition. J. Atmos. Sci., 54, 168-192.

Wylie, D., 2001: Arctic weather during the FIRE/ACE flights in 1998. J. Geophys. Res., 106 (D14), 15 363-15 375.

Yano, J., and V. T. J. Phillips, 2011: Ice-ice collisions: An ice multiplication process in atmospheric clouds. J. Atmos. Sci., 68, 322-333.

Yuan, J., Q. Fu, and N. McFarlane, 2006: Tests and improvements of GCM cloud parameterizations using the CCCMA SCM with the SHEBA data set. Atmos. Res., 82 (1-2), 222-238.

Yum, S., and J. G. Hudson, 2001: Vertical distributions of cloud condensation nuclei spectra over the springtime Arctic Ocean. J. Geophys. Res., 106 (D14), 15 045-15 052.

Zhang, T., K. Stamnes, and S. A. Bowling, 1996: Impact of clouds on surface radiative fluxes and snowmelt in the Arctic and subarctic. J. Climate, 9, 2110-2123.

Zuidema, P., and Coauthors, 2005: An Arctic springtime mixedphase boundary layer observed during SHEBA. J. Atmos. Sci., 62, 160-176. 